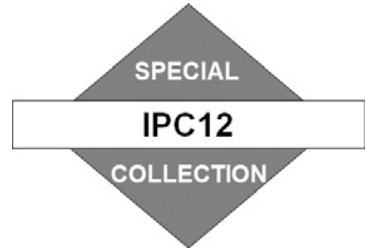

\title{
๖The Passive Microwave Empirical Cold Surface Classification Algorithm (PESCA): Application to GMI and ATMS
}

\author{
Andrea Camplani,${ }^{\mathrm{a}, \mathrm{b}}$ Daniele Casella,,${ }^{\mathrm{a}}$ Paolo Sanò, ${ }^{\mathrm{a}}$ And Giulia Panegrossi ${ }^{\mathrm{a}}$ \\ a Institute of Atmospheric Sciences and Climate, National Research Council, Rome, Italy \\ ${ }^{\mathrm{b}}$ Geodesy and Geomatics Division, Sapienza University of Rome, Rome, Italy
}

(Manuscript received 30 October 2020, in final form 13 April 2021)

\begin{abstract}
This paper describes a new Passive Microwave Empirical Cold Surface Classification Algorithm (PESCA) developed for snow-cover detection and characterization by using passive microwave satellite measurements. The main goal of PESCA is to support the retrieval of falling snow, since several studies have highlighted the influence of snow-cover radiative properties on the falling-snow passive microwave signature. The developed method is based on the exploitation of the lower-frequency channels $(<90 \mathrm{GHz})$, common to most microwave radiometers. The method applied to the conically scanning Global Precipitation Measurement (GPM) Microwave Imager (GMI) and the cross-track-scanning Advanced Technology Microwave Sounder (ATMS) is described in this paper. PESCA is based on a decision tree developed using an empirical method and verified using the AutoSnow product built from satellite measurements. The algorithm performance appears to be robust both for sensors in dry conditions (total precipitable water $<10 \mathrm{~mm}$ ) and for mean surface elevation $<$ $2500 \mathrm{~m}$, independent of the cloud cover. The algorithm shows very good performance for cold temperatures (2-m temperature below $270 \mathrm{~K}$ ) with a rapid decrease of the detection capabilities between 270 and $280 \mathrm{~K}$, where $280 \mathrm{~K}$ is assumed as the maximum temperature limit for PESCA (overall detection statistics: probability of detection is 0.98 for ATMS and 0.92 for GMI, false alarm ratio is 0.01 for ATMS and 0.08 for GMI, and Heidke skill score is 0.72 for ATMS and 0.69 for GMI). Some inconsistencies found between the snow categories identified with the two radiometers are related to their different viewing geometries, spatial resolution, and temporal sampling. The spectral signatures of the different snow classes also appear to be different at high frequency $(>90 \mathrm{GHz})$, indicating potential impact for snowfall retrieval. This method can be applied to other conically scanning and cross-track-scanning radiometers, including the future operational EUMETSAT Polar System Second Generation (EPS-SG) mission microwave radiometers.
\end{abstract}

KEYWORDS: Snow; Snow cover; Snowfall; Microwave observations; Remote sensing; Satellite observations

\section{Introduction}

Snow plays an important role in the Earth energy exchange processes and is a fundamental element of the water cycle. Higher-latitude regions are experiencing significant modifications related to climate change. While the effect on temperatures is relatively well known, the impacts on precipitation, snow/ice extent, and snow/ice properties are less documented and less understood. The use of satellites for snowfall monitoring and quantification and for retrieving snow-cover properties and variability is necessary to globally quantify water resources (Levizzani et al. 2011; Skofronick-Jackson and Johnson 2011; Romanov et al. 2003).

Spaceborne multichannel microwave (MW) radiometers are the only sensors able to provide consistent measurements of falling snow and snow-cover properties at the same time, and therefore to contribute to the understanding of their feedback

¿ Denotes content that is immediately available upon publication as open access.

Corresponding author: Daniele Casella, d.casella@isac.cnr.it mechanisms and interconnections in hydrology and climate. On one side, the high-frequency channels $(90-190 \mathrm{GHz})$ are sensitive to falling snow due to the scattering by snowflakes of upwelling radiation (e.g., Bennartz and Bauer 2003; Liu and Seo 2013; Skofronick-Jackson and Johnson 2011). On the other side, the lower-frequency channels $(<90 \mathrm{GHz})$ allow to characterize and quantify snow-cover properties (e.g., Grody 1991; Ferraro et al. 2005). Moreover, their large swath and availability on many platforms ensures a good global coverage and lengthy data records.

The snowpack microwave signal has been studied since the late 1970s (e.g., Stiles and Ulaby 1980; Hallikainen et al. 1986). The snow-covered surfaces show MW emissivity spectra that are extremely variable, due to the nature of snowpack as an inhomogeneous layered medium. A snowpack is an inhomogeneous mixture of air, ice, and water (Colbeck 1976). Deposition and metamorphic processes are responsible for the creation of layers (Pielmeier and Schneebeli 2003) that are subject to modifications due to metamorphic processes over time (Colbeck 1991), caused by mechanical compression, thermal gradients in the snowpack and melting (Arons and Colbeck 1995). In the MW spectrum dry snow acts as a volume scatterer, because of the discontinuities between air and ice (Amlien 2008). The dry 

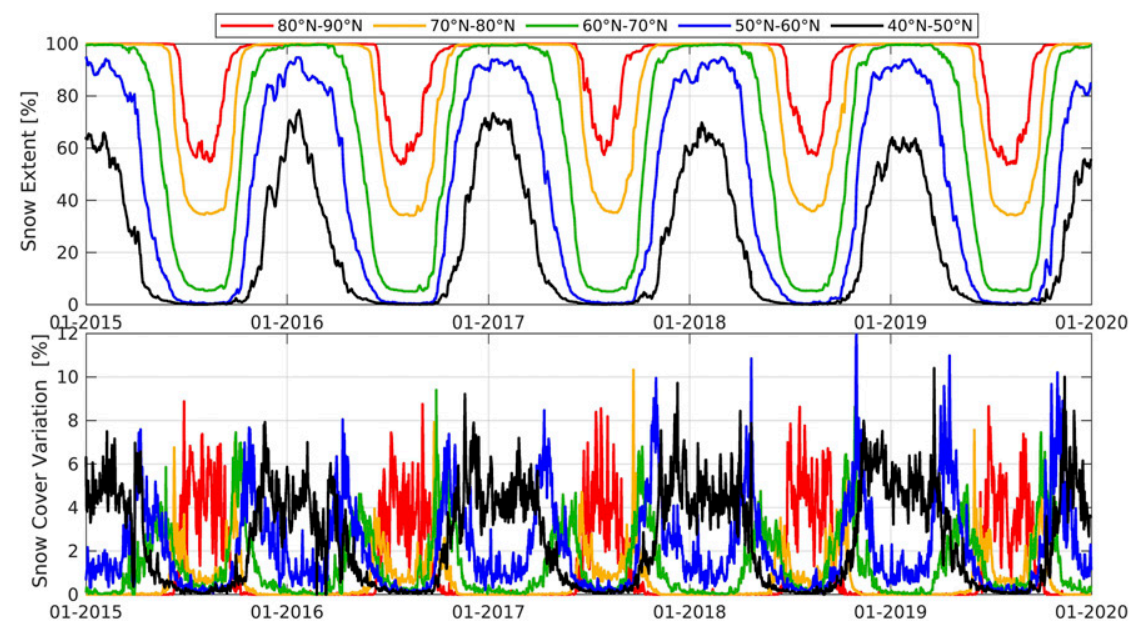

FIG. 1. Analysis of 5 years of AutoSnow snow-cover product over the Northern Hemisphere. (top) Snow extent percentage w.r.t. total land extent. (bottom) Snow extent daily change (in percentage w.r.t. total land extent) for the same latitude bins. The different curves refer to the five different $10^{\circ}$ latitude bins indicated in the legend.

snow grain size and shape influence its scattering properties (Foster et al. 1999; Clifford 2010). While the depth of the dry snowpack strongly influences the total amount of radiation that is scattered (Che et al. 2008), the liquid water within the snowpack strongly enhances the absorption at the expense of the volume scattering (Rott and Nagler 1995; Amlien 2008). Hewison and English (1999) developed a model representing the microwave emissivity spectra of sea ice and snow cover obtained by airborne measurements. Different behaviors have been observed for different types of snowpacks, with an evident decrease of the emissivity with increasing frequency (within MW) for dry snow, and a high and stable emissivity for fresh wet snow.

Many products and algorithms already exist for the detection of snow cover from satellite. Most of them make use either of infrared and visible (VIS/IR) channels [e.g., MODIS (Hall and Riggs 2007; Hall et al. 1995, 2002; Riggs et al. 2006), GlobSnow (Metsämäki et al. 2015)] or a combination of MW and VIS/IR measurements [e.g., Prigent et al. (2003) or the Global Multisensor Automated Snow and Ice Maps (GMASI) AutoSnow product (Romanov 2017)]. Some snow-cover detection algorithms based only on MW radiometers already exist (e.g., Chang et al. 1987; Grody 1991; Walker and Goodison 1993; Grody and Basist 1996; Kelly et al. 2003; Ferraro et al. 2005). However, in recent years there has been a lack of new MW-based studies despite the need for snow-cover detection and characterization for passive MW precipitation estimates. Some wide and active areas of research are related to MW-based retrieval of snow properties, in particular the characterization of snow emissivity (e.g., Cordisco et al. 2006; Prigent et al. 2008; Munchak et al. 2020, hereinafter M20), and the estimate of snow depth (SD) and snow water equivalent (SWE) (e.g., Chang et al. 1987; Foster et al. 1997; Markus et al. 2006; Tedesco et al. 2010).

The snow-cover extent, especially in the ablation and accumulation season, shows a high variability often within the same day. A striking example of such variability is provided in Fig. 1. It shows a 5-yr analysis of the AutoSnow daily snow-cover product (Romanov 2017) in the Northern Hemisphere. The top panel shows the variability of the snow-cover area (or snow extent) percentage (with respect to the total land area), for five $10^{\circ}$-latitude bins, while the lower panel shows the snow extent daily change, i.e., the area of snow cover that experiences a variation from one day with respect to the previous day (in percentage with respect to the total land area), for the same latitude bins. It is clear from Fig. 1 that the snow extent daily variability is a relatively large fraction (up to $10 \%$ ) of the total land area. This is particularly true for the ablation and deposition seasons (spring and autumn), with different durations depending on the latitude.

The extremely variable snow-cover extent and snow radiative properties in the MW are one of the main issues in the detection and quantification of snowfall by passive microwave observations, which remain among the most challenging tasks in global precipitation retrieval (Bennartz and Bauer 2003; Skofronick-Jackson et al. 2004, 2019; Noh et al. 2009; Levizzani et al. 2011; Kongoli and Helfrich 2015; Chen et al. 2016; You et al. 2017; Kulie et al. 2016; and many others). On one side, relative to rainfall, the snowfall scattering signal is much weaker (Grody 1991; Kim et al. 2008; Kulie et al. 2010), is highly dependent on the complex microphysical characteristics of snowfall (Bennartz and Petty 2001; Liu 2008; Kulie et al. 2010; Petty and Huang 2010; Skofronick-Jackson and Johnson 2011; Kuo et al. 2016; Olson et al. 2016; Eriksson et al. 2018; Kneifel et al. 2020), and tends to be masked by the atmospheric and liquid water emissivity (Kneifel et al. 2010; Johnson et al. 2016; Liu and Seo 2013; Wang et al. 2013; Panegrossi et al. 2017). On the other side, the snow-covered surface emissivity is extremely variable due to rapid changes of snow-cover extent, snow accumulation on the ground, and snowpack radiative properties, with significant effects on the snowfall microwave signal (e.g., Laviola et al. 2015; Prigent et al. 2003; Noh et al. 2009; Takbiri et al. 2019; M20). The falling-snow weak signal has to be distinguished from the highly variable surface signal, 
therefore a characterization of the surface is vital to a successful snowfall detection. Moreover, it has been demonstrated that a nonunique and nonmonotonic response exists between the TBs and snowfall rate over different snow-covered surfaces (Takbiri et al. 2019), with a variable contrast between the surface and the clouds, and a transition from a scattering to an emission regime, that is strongly dependent on the snow-cover dynamics. Passive microwave (PMW) snowfall retrieval algorithms often rely on the use of climatological microwave emissivity datasets (e.g., Prigent et al. 2008), often used in conjunction with daily products for snow-cover extent (and sea ice concentration). Several recent studies show how critical the correct characterization of the surface conditions at the time of the satellite overpass is for precipitation estimation from PMW radiometer observations (e.g., Milani et al. 2020; Ringerud et al. 2021). For snowfall detection and retrieval this is even more critical, because the highly variable snow surface conditions have a time-varying effect on the snowfall upwelling signal (Ebtehaj and Kummerow 2017; Takbiri et al. 2019), and this should be considered in the snowfall retrieval process. A first attempt to account for such variability has been made in a recently developed snowfall retrieval algorithm for the Global Precipitation Measurement (GPM) Microwave Imager (GMI) [Snow Retrieval Algorithm for GMI (SLALOM); Rysman et al. 2018, 2019] where no assumptions on the background surface are made, and where the GMI low-frequency channels are used to optimally exploit the snowfall-related signal at high frequency.

The main goal of this work is to describe a new snow-cover detection and classification algorithm, the Passive Microwave Empirical Cold Surface Classification Algorithm (PESCA), based on a decision tree built on a series of tests on low-frequency MW channels and their combinations, selected on the basis of previous studies on the MW spectrum dependencies on snowpack physical conditions. The most useful aspect of the algorithm is that it exploits channel frequencies common to most current and future microwave radiometers in space (from 23 to $90 \mathrm{GHz}$ ), and that it can be applied to both conically scanning and cross-track-scanning radiometers. In this study a comparison between the results obtained for the conically scanning GMI and those obtained for the cross-track-scanning Advanced Technology Microwave Sounder (ATMS) radiometers is analyzed. The study aims at highlighting the potential application of the method in snowfall retrieval algorithms in dry conditions, where the characterization of the snow cover at the time of the overpass is a prerequisite for the full exploitation of the high-frequency channels used for the retrieval.

\section{Data and methods}

The work is based on the use of three different datasets (for development, validation, and analysis) obtained by combining the observations from the PMW sensors (GMI and ATMS) with model-derived environmental variables and snow-cover products used as reference.

\section{a. Instruments and reference products}

The two most advanced microwave radiometers currently in space, which are part of the GPM constellation, have been considered in this study: the GMI (Draper et al. 2015) on board the NASA/JAXA GPM Core Observatory and the ATMS (Weng et al. 2012) on board the operational Suomi National Polar Orbit Partnership (SNPP) and NOAA-20 U.S. satellites. The main characteristics of GMI and ATMS are summarized in Tables 1 and 2. Note that the two MW radiometers have very different characteristics: GMI is a non-sun-synchronous conically scanning radiometer with a constant viewing angle covering a 904-km-wide swath, and ATMS is a cross-track-scanning radiometer, on board sun synchronous polar satellites, with viewing angles ranging between $0^{\circ}$ and $52.77^{\circ}$, covering a $2600-\mathrm{km}$-wide swath. The NASA Precipitation Processing System (PPS) intercalibrated brightness temperatures (TBs), Level 1C-R and $1 \mathrm{C}$ for GMI and ATMS, respectively (Berg et al. 2016), are used in the study. In particular, the TBs measured at 23.8, 36.5, and $89 \mathrm{GHz}$ (V polarization channels) (hereinafter $\mathrm{TB}_{23 \mathrm{~V}}, \mathrm{~TB}_{37 \mathrm{~V}}$, and $\mathrm{TB}_{89 \mathrm{v}}$ ) for GMI, and at 23.8, 31.4, and $88.2 \mathrm{GHz}$ (quasi-V polarization channels) $\left(\mathrm{TB}_{23 \mathrm{QV}}, \mathrm{TB}_{31 \mathrm{QV}}\right.$, and $\left.\mathrm{TB}_{88 \mathrm{QV}}\right)$ for ATMS are used. The "quasi" prefix is used to indicate the ATMS (and other crosstrack scanners) channels because it measures vertical polarization when looking at nadir and a mixture of $\mathrm{V}$ and $\mathrm{H}$ polarization for off-nadir scan angles, according to the following equation:

$$
\mathrm{TB}_{\mathrm{QV}}=\mathrm{TB}_{V} \cos ^{2}(\theta)+\mathrm{TB}_{H} \sin ^{2}(\theta),
$$

where $\theta$ is the scan angle.

Table 1 also reports some characteristics of the W-band (94 GHz) CloudSat Cloud Profiling Radar (CPR) relevant for this study [see section $2 \mathrm{~b}(1)$ ]. The CPR has been used to infer the status of the cloud cover at the time and location of the PMW observation. As demonstrated in several studies, CPR high sensitivity allows one to observe light precipitation and snowfall at high latitudes (e.g., Kulie and Bennartz 2009; Casella et al. 2017; Skofronick-Jackson et al. 2019; Liu 2020), although shallow snowfall events could be partly missed because of ground clutter contamination (Milani et al. 2018; Bennartz et al. 2019).

Two different reference snow-cover products have been used in the study, one global and one over the contiguous United States (CONUS) region. The global AutoSnow product is provided by the Global Multisensor Automated Snow and Ice maps (GMASI; Romanov 2017) algorithm, for ice and snow-cover detection, developed by the NOAA/NWS and National Ice Center (NIC) to support the hydrological community. It consists of global and daily snow-cover and sea ice maps with a spatial resolution of $0.04^{\circ}$. It is based on the combination of four different GEO and LEO sensors, VIS/IR AVHRR, GOES-E, GOES-W, SEVIRI in the VIS/IR, and the SSMIS MW radiometer. A specific algorithm processes data from each instrument and the results are combined. In particular, the microwave estimates are used only to fill the gaps due to the lack of VIS/IR-based estimates (at night time or due to the presence of clouds). AutoSnow daily maps are conventionally referred to 0000 UTC. The maps present four surfacetype flags, snow cover, snow-free land, clear water, ice cover, and one flag for invalid data. The agreement between AutoSnow yearly mean and surface observations over CONUS has been estimated in $91.4 \%$ (Nagler et al. 2014). 
TABLE 1. Main characteristics of GMI and ATMS MW radiometers and CloudSat CPR.

\begin{tabular}{|c|c|c|c|}
\hline & GMI & ATMS & CPR \\
\hline Name & GPM Microwave Imager & $\begin{array}{l}\text { Advanced Technology Microwave } \\
\text { Sounder }\end{array}$ & Cloud Profiling Radar \\
\hline Satellite & $\begin{array}{l}\text { Global Precipitation Measurement } \\
\text { (GPM) Core Observatory }\end{array}$ & $\begin{array}{l}\text { Suomi National Polar Orbit Partnership } \\
\quad(\text { SNPP })-N O A A-20\end{array}$ & CloudSat \\
\hline Scanning technique & $\begin{array}{l}\text { Conically scanning microwave } \\
\text { radiometer }\end{array}$ & $\begin{array}{l}\text { Cross-track-scanning microwave } \\
\text { radiometer }\end{array}$ & Nadir-looking cloud radar \\
\hline $\begin{array}{l}\text { Channels and } \\
\text { frequencies }\end{array}$ & $\begin{array}{l}13 \text { channels (from } 10 \text { to } 190 \mathrm{GHz} \text { ) } \\
\text { (with } 5 \text { window channels in } V \text { and } \\
H \text { polarization) }\end{array}$ & $\begin{array}{l}22 \text { channels (from } 23 \text { to } 190 \mathrm{GHz} \text { ) } \\
\text { (13 channels in the } 50-60-\mathrm{GHz} \\
\text { band for temperature sounding) }\end{array}$ & $94 \mathrm{GHz}$ \\
\hline $\begin{array}{l}\text { Spatial resolution (3-db } \\
\text { footprint IFOV size) }\end{array}$ & $\begin{array}{l}19 \times 32 \mathrm{~km}^{2}-4 \times 7 \mathrm{~km}^{2} \text { increasing } \\
\text { with frequency }\end{array}$ & $\begin{array}{l}75 \times 75 \mathrm{~km}^{2}-16 \times 16 \mathrm{~km}^{2} \text { at nadir } \\
\text { increasing with frequency, degrading } \\
\text { from nadir to the edges }\end{array}$ & $\begin{array}{l}\text { 1.4-km horizontal; } \\
\text { 240-m vertical }\end{array}$ \\
\hline Viewing angle & $\begin{array}{l}48.5^{\circ}\left(45.3^{\circ} \text { channels from } 166 \text { to }\right. \\
183 \mathrm{GHz})\end{array}$ & from $0^{\circ}$ to $52.77^{\circ}$ & \\
\hline Swath & $904 \mathrm{~km}$ & $2600 \mathrm{~km}$ & \\
\hline Orbit inclination & $\begin{array}{l}\text { Drifting orbit } 65^{\circ} \text { inclination } \\
\text { (polar areas not covered) }\end{array}$ & Sun synchronous & $\begin{array}{l}\text { Sun synchronous (from } \\
83^{\circ} \mathrm{S} \text { to } 83^{\circ} \mathrm{N} \text { ) }\end{array}$ \\
\hline Revisiting Time & 2 days & $12 \mathrm{~h}$ & 16 days \\
\hline Launch Date & 28 Feb 2014 & 6 Mar 2012 & 28 Apr 2006 \\
\hline
\end{tabular}

The regional Snow Data Assimilation System (SNODAS; Carroll et al. 2006) is a modeling and data assimilation system developed by the National Operational Hydrologic Remote Sensing Center (NOHRSC) to support hydrologic modeling and analysis over Contiguous United States (CONUS) (from $24^{\circ}$ to $54^{\circ} \mathrm{N}$, and from $131^{\circ}$ to $62^{\circ} \mathrm{W}$ ). SNODAS provides a physically consistent framework to integrate snow data from satellites, airborne platforms, and ground stations with model estimates of snow-cover state variables at a daily temporal resolution, and $1 \mathrm{~km}$ spatial resolution: three state variables (describing the surface status at 0600 UTC), SWE, SD, and snowpack average temperature; two driving variables (reporting the total value for the previous $24 \mathrm{~h}$ ), solid and liquid precipitation; and three diagnostic variables (model outputs cumulated in $24 \mathrm{~h}$ ), snowmelt runoff at the base of the snowpack, sublimation from the snowpack and sublimation of blowing snow. Results from snow surveys in the Colorado Rocky Mountains (Clow et al. 2012) indicated that SNODAS performed well in forested nonmountainous areas, explaining $72 \%$ of the variance in snow depth and $77 \%$ of the variance in SWE.
The development of PESCA has been based on the use of AutoSnow as reference for snow-cover detection. The validation of the algorithm is based on the use of an independent and larger AutoSnow dataset. SNODAS has been used for a regional analysis of some physical properties of PESCA snow classes, that is, SD, snow precipitation and melted snow mass in the last $24 \mathrm{~h}$. It is worth noting that both reference products are available at daily time scale, therefore in case of subdaily variations (e.g., due to snow accumulation or snow melting) PESCA could actually be correct while disagreeing with the reference data.

\section{b. Dataset description}

The main characteristics of the three datasets used in this study are summarized in Table 3.

\section{1) Development dataset (AutoSnow, CPR, PMW)}

The development dataset has been used first for the development and tuning of the snow detection algorithm and secondarily to analyze the influence of the cloud cover on the algorithm snow detection capabilities. The development dataset has been

TABLE 2. GMI and ATMS channel characteristics (pol indicates polarization).

\begin{tabular}{|c|c|c|c|c|c|}
\hline \multicolumn{3}{|c|}{ GMI } & \multicolumn{3}{|c|}{ ATMS } \\
\hline Frequency $(\mathrm{GHz})$ & Footprint $(\mathrm{km})$ & Pol & Frequency $(\mathrm{GHz})$ & Footprint $(\mathrm{km})$ & Pol \\
\hline 10.65 & $19 \times 32$ & $\mathrm{~V} ; \mathrm{H}$ & 23.8 & $75 \times 75$ & QV \\
\hline 18.7 & $11 \times 18$ & $\mathrm{~V} ; \mathrm{H}$ & 31.4 & $75 \times 75$ & QV \\
\hline 23.8 & $9.2 \times 15$ & V & 88.2 & $32 \times 32$ & QV \\
\hline 36.5 & $8.6 \times 14$ & $\mathrm{~V} ; \mathrm{H}$ & 165.5 & $16 \times 16$ & $\mathrm{QH}$ \\
\hline 89.0 & $4.4 \times 7.2$ & $\mathrm{~V} ; \mathrm{H}$ & $183.31 \pm 1$ & $16 \times 16$ & $\mathrm{QH}$ \\
\hline 166.5 & $4.4 \times 7.2$ & V & $183.31 \pm 1.8$ & $16 \times 16$ & $\mathrm{QH}$ \\
\hline $183.31 \pm 7$ & $4.4 \times 7.2$ & $\mathrm{~V}$ & $183.31 \pm 3$ & $16 \times 16$ & $\mathrm{QH}$ \\
\hline \multirow{2}{*}{$183.31 \pm 3$} & $4.4 \times 7.2$ & $\mathrm{~V}$ & $183.31 \pm 4.5$ & $16 \times 16$ & $\mathrm{QH}$ \\
\hline & & & $183.31 \pm 7$ & $16 \times 16$ & $\mathrm{QH}$ \\
\hline
\end{tabular}


TABLE 3. Characteristics of the development, validation, and analysis datasets used for ATMS and GMI. In parentheses is the percentage of observations with snow cover according to the AutoSnow reference dataset. The spatial resolution indicates the assumed ATMS and GMI IFOV size used to spatially average reference-truth products and CPR products and match the radiometer measurements. Note that $180^{\circ}-180^{\circ}$ indicates that the longitudinal coverage spans the globe.

\begin{tabular}{ccccccc}
\hline \hline Dataset & PMW sensor & No. of obs $(\%$ snow cover) & \multicolumn{2}{c}{ Spatial coverage (lat/lon) } & Spatial resolution & Temporal coverage \\
\hline Development & ATMS & $4.67 \times 10^{6}(10.4 \%)$ & $83^{\circ} \mathrm{S}-83^{\circ} \mathrm{N}$ & $180^{\circ}-180^{\circ}$ & $75 \times 75 \mathrm{~km}^{2}$ & $1 \mathrm{Jan} 2015-31 \mathrm{Aug} 2016$ \\
& GMI & $1.57 \times 10^{5}(11.5 \%)$ & $67^{\circ} \mathrm{S}-67^{\circ} \mathrm{N}$ & $180^{\circ}-180^{\circ}$ & $10 \times 15 \mathrm{~km}^{2}$ & $1 \mathrm{Jan} 2015-31 \mathrm{Aug} 2016$ \\
Validation & ATMS & $1.37 \times 10^{8}(16.2 \%)$ & $90^{\circ} \mathrm{S}-90^{\circ} \mathrm{N}$ & $180^{\circ}-180^{\circ}$ & $75 \times 75 \mathrm{~km}^{2}$ & $1 \mathrm{Jan} 2015-31 \mathrm{Dec} 2015$ \\
& GMI & $1.02 \times 10^{9}(26.7 \%)$ & $67^{\circ} \mathrm{S}-67^{\circ} \mathrm{N}$ & $180^{\circ}-180^{\circ}$ & $10 \times 15 \mathrm{~km}^{2}$ & $1 \mathrm{Jan} 2015-31 \mathrm{Dec} 2015$ \\
\multirow{2}{*}{ Analysis } & ATMS & $4,69 \times 10^{6}(7.73 \%)$ & $24^{\circ}-54^{\circ} \mathrm{N}$ & $131^{\circ}-62^{\circ} \mathrm{W}$ & $75 \times 75 \mathrm{~km}^{2}$ & $1 \mathrm{Jan} 2015-31 \mathrm{Dec} 2015$ \\
& GMI & $2.25 \times 10^{7}(8.25 \%)$ & $24^{\circ}-54^{\circ} \mathrm{N}$ & $131^{\circ}-62^{\circ} \mathrm{W}$ & $10 \times 15 \mathrm{~km}^{2}$ & $1 \mathrm{Jan} 2015-04 \mathrm{Dec} 2016$ \\
\hline
\end{tabular}

obtained from the coincidences between CloudSat CPR and SNPP ATMS or GMI (Turk 2016) for the period January 2015-August 2016. The dataset includes several CPR products (e.g., snow water path, snowfall rate at the surface from the 2C-SNOW-PROFILE product; Wood and L'Ecuyer 2018); however, in this study only the CPR cloud mask from the 2BGEOPROF product is used. The AutoSnow maps are included in the development dataset as reference for snow cover. Both AutoSnow and CPR observations have been spatially averaged using a Gaussian antenna pattern to match the ATMS/GMI instantaneous field of view (IFOV). For each ATMS/GMI observation five occurrence indices, given by the fraction of each AutoSnow class (snow cover, snow-free land, clear water, ice cover, and invalid data) in the PMW IFOV, are provided. Some environmental variables from ERA5 (interpolated in time and space to the radiometer IFOV position) have been added to the dataset: temperature at the 2-m level $\left(T_{2 \mathrm{~m}}\right)$, skin temperature $\left(T_{\text {skin }}\right)$ and total precipitable water (TPW). The dataset also includes surface elevation (height MSL) from a digital elevation model (DEM) (GTOPO30; https://doi.org/ 10.5066/F7DF6PQS). The surface elevation has been also averaged with a Gaussian antenna pattern to match the ATMS/GMI IFOV.

\section{2) Validation dataset (AutoSnow, PMW)}

The validation dataset has been built by combining GMI/ATMS observations with AutoSnow surface maps, GTOPO30 DEM, and ERA5 environmental variables $\left(T_{2 \mathrm{~m}}, T_{\text {skin }}\right.$, and TPW) using the same procedure described for the development dataset. This dataset has been used for the assessment of PESCA snow-cover detection capabilities after removing all observations already included in the development dataset.

\section{3) AnAlysis dataset (SNODAS, PMW)}

The analysis dataset has been used to identify and interpret the physical characteristics of the different classes of snow cover identified by the algorithm. It has been developed by combining ATMS or GMI observations with SNODAS output variables, GTOPO30 DEM, and ERA5. Since SNODAS is available only over CONUS, all the results based on this dataset are valid at a regional scale. While all sun synchronous GMI orbits over CONUS have been considered, only ATMS ascending orbits (between 0600 and 1300 UTC), closest in time to the SNODAS reference time (0600 UTC), have been selected. The dataset has been built following the same procedures used for the development and validation datasets, obtaining a snow-cover occurrence index, a land fraction index (since SNODAS provides information only over land) and a mean value (over the PMW IFOV) of SNODAS snow-related variables.

\section{Algorithm description}

The PESCA method developed for snow-cover classification is based on a decision tree built from five different tests. It makes use of a limited number of inputs that have been recognized as very important for the detection of snow cover and for the characterization of its physical properties. The first input is the low-frequency ratio $\left(R_{\mathrm{LF}}\right)$, which is the ratio between $\mathrm{TB}_{23 \mathrm{~V}} / \mathrm{TB}_{37 \mathrm{~V}}$ for GMI and the ratio $\mathrm{TB}_{23 \mathrm{QV}} / \mathrm{TB}_{31 \mathrm{QV}}$ for ATMS. As previously described, many authors have noticed that a steep decrease in the low-frequency channel emissivity with increasing frequency $(<37 \mathrm{GHz})$ is a clear indication of the presence of Deep Dry Snow (e.g., Markus et al. 2006). The $R_{\mathrm{LF}}$ has the same physical meaning as $\Delta \mathrm{TB}$, considering the use of vertical instead of horizontal polarization channels, and negative $\Delta \mathrm{TB}$ corresponds to $R_{\mathrm{LF}}<1.01$. The second input is the scattering index (SI). Grody and Basist (1996) used SI from $\mathrm{SSM} / \mathrm{I}$ defined as $\mathrm{TB}_{22 \mathrm{v}}-\mathrm{TB}_{85 \mathrm{v}}$ to identify the snow-covered surfaces. The SI, however, fails in detecting polar ice sheets (over Greenland and Antarctica) and a different test is performed on the low-frequency channel brightness temperature $\left(\mathrm{TB}_{\mathrm{LF}}: \mathrm{TB}_{23 \mathrm{~V}}\right.$ and $\mathrm{TB}_{23 \mathrm{QV}}$ for GMI and ATMS, respectively) to identify snow in these regions. Starting from these guidelines we have analyzed the development dataset and identified different data clusters in the space of these variables corresponding to different snow classes. Then, for each cluster, we have developed a series of discriminant tests to distinguish between the various snow classes and snow-free land. This method is somewhat similar to what has been done by other authors (e.g., Cordisco et al. 2006; Wang et al. 2017) using unsupervised clustering methods; however, our algorithm has not been developed using fully automated clustering tools, but manually optimizing each test (see Fig. 3 for two examples) depending on the partitioning of snow and no-snow pixels according to the reference product (AutoSnow).

Four snow classes have been named by analyzing their seasonal and geographical distribution and their characteristics in terms of snow depth [verified also using the analysis dataset over CONUS; see section $4 \mathrm{~b}(1)]$ : 


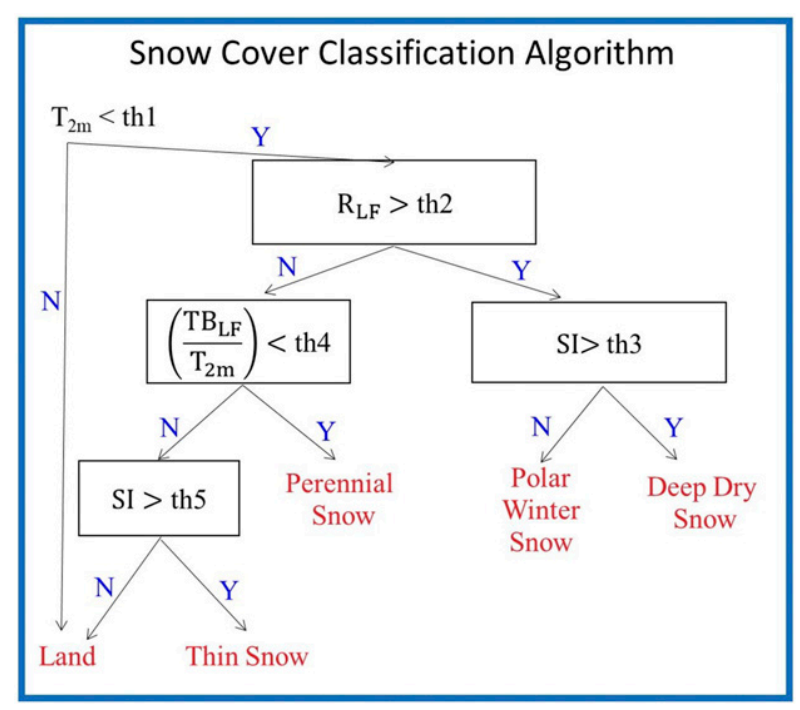

FIG. 2. Decision tree of the PESCA snow-cover detection and classification scheme.

1) Deep Dry Snow-Seasonal snow with moderate to deep dry snow depth, radiometrically characterized by $R_{\mathrm{LF}}>1.01$ and by strong scattering at $\sim 90 \mathrm{GHz}$ (high SI) (C in the left panel of Fig. 3).

2) Polar Winter Snow-This class of snow has been found only in the inner Antarctica and Greenland Plateaus in the winter season and falls outside the GMI coverage area. It is characterized by $R_{\mathrm{LF}}>1.01$ and by low SI (B in the left panel of Fig. 3).

3) Perennial Snow-Present mostly at higher latitudes and at low temperatures, characterized by $R_{\mathrm{LF}}<1.01$ and by significant scattering at low frequency $(19-23 \mathrm{GHz})$. It is probably related to old snow with deep hoar, recognized by Grody and Basist (1996) as "glacial arctic ice" (D in the right panel of Fig. 3).

4) Thin Snow-It is a seasonal snow associated with the smallest retrievable thickness and it is only visible from scattering at relatively high frequency (A in the right panel of Fig. 3).

Figure 2 shows the algorithm flowchart. The decision tree scheme is the same for GMI and ATMS, while the definition of the input variables and thresholds tailored for the specific radiometer are listed in Table 4. The first test (Test 1) is on the $T_{2 \mathrm{~m}}$ and considers all pixels with temperatures higher than $280 \mathrm{~K}$ as snow free, as a small fraction $(0.6 \%$ for ATMS, $1.6 \%$ for GMI) of the datasets include snow cover with $T_{2 \mathrm{~m}}>280 \mathrm{~K}$. The second test (Test 2) is on the $R_{\mathrm{LF}}$, where $R_{\mathrm{LF}}>$ th2 (th2 $=1.01$ for both GMI and ATMS) identifies snow pixels with stronger volume scattering at $31-37 \mathrm{GHz}$ than at $23 \mathrm{GHz}$. For these pixels, a test on the SI (Test 3 ) is carried out and two clusters of snow cover are identified (Deep Dry Snow and Polar Winter Snow). If the $R_{\mathrm{LF}} \leq 1.01$, the algorithm proceeds in testing the $\mathrm{TB}_{\mathrm{LF}}$ (Test 4 ) and identifies the Perennial Snow Class. If both the $R_{\mathrm{LF}}>1.01$ and the $\mathrm{TB}_{\mathrm{LF}}$ tests fail, the $\mathrm{SI}$ is used in order to identify Thin Snow (Test 5). The last test is the
TABLE 4. PESCA parameters and thresholds used in the five snow-cover detection tests for GMI and ATMS.

\begin{tabular}{lcc}
\hline \hline Variable & GMI & ATMS \\
\hline $\mathrm{R}_{\mathrm{LF}}$ & $\mathrm{TB}_{23 \mathrm{~V}} / \mathrm{TB}_{37 \mathrm{~V}}$ & $\mathrm{~TB}_{23 \mathrm{QV}} / \mathrm{TB}_{31 \mathrm{QV}}$ \\
$\mathrm{SI}$ & $\mathrm{TB}_{23 \mathrm{~V}}-\mathrm{TB}_{89 \mathrm{~V}}$ & $\mathrm{~TB}_{23 \mathrm{QV}}-\mathrm{TB}_{88 \mathrm{QV}}$ \\
$\mathrm{TB}_{\mathrm{LF}}$ & $\mathrm{TB}_{23 \mathrm{~V}}$ & $\mathrm{~TB}_{23 \mathrm{QV}}$ \\
th 1 & $280 \mathrm{~K}$ & $280 \mathrm{~K}$ \\
th 2 & 1.01 & 1.01 \\
th 3 & - & $257-T_{2 \mathrm{~m}}(\mathrm{~K})$ \\
th 4 & $\left(495 \mathrm{~K}-T_{2 \mathrm{~m}}\right) /(250 \mathrm{~K})$ & $\left(465 \mathrm{~K}-T_{2 \mathrm{~m}}\right) /(225 \mathrm{~K})$ \\
th 5 & $5 \mathrm{~K}$ & $3 \mathrm{~K} / \cos (\theta)$ \\
\hline
\end{tabular}

most problematic: first because the MW signal associated with the presence of Thin Snow is weaker than for other classes, and secondarily due to the extremely variable conditions of Thin Snow coverage in time and space that causes larger uncertainties in the reference dataset and inhomogeneity within the satellite IFOV. This issue is particularly problematic for ATMS because of its low spatial resolution.

Figure 3 shows an example of the method followed for the definition of the test in the ATMS algorithm. In both panels the letter A indicates the assumed snow-free land pixels $\left(T_{2 \mathrm{~m}}>280 \mathrm{~K}\right)$. The left panel illustrates the density scatterplots of the snow-cover clusters identified when $R_{\mathrm{LF}}>1.01$ in the $T_{2 \mathrm{~m}}$ versus SI space. In this panel two main snow clusters are clearly visible (labeled with letters B and C), discriminated by a line (shown in dark green) corresponding to Test 3 (SI $>$ th3), and associated to Deep Dry Snow and Polar Winter Snow, respectively. The left panel also shows the contours of the number of snow-free observations (very few and mostly found at $T_{2 \mathrm{~m}}>270 \mathrm{~K}$ ). The right panel shows the density scatterplots in the $T_{2 \mathrm{~m}}$ versus $\mathrm{TB}_{\mathrm{LF}} / T_{2 \mathrm{~m}}$ (23-GHz pseudoemissivity) space, for the observations that verify the condition: $R_{\mathrm{LF}} \leq 1.01$. The two identified snow-cover clusters are labeled with the letter D (corresponding to Perennial Snow) and letter E (including Thin Snow and snow-free land) that are discriminated by Test 4 $\left(\mathrm{TB}_{\mathrm{LF}} / T_{2 \mathrm{~m}}<\mathrm{th} 4\right)$. Also in this case the contours correspond to the number of snow-free observations, showing a high overlap with the snow-cover region of cluster E. Test 5 (SI $>$ th5) (not shown) is conducted on observations in cluster $\mathrm{E}$ as a further step to discriminate between Thin Snow and snow-free land. It is worth noting that some snow-covered areas are present for $T_{2 \mathrm{~m}}>280 \mathrm{~K}$ and are missed by PESCA.

Table 4 shows the thresholds that have been empirically determined for ATMS and GMI. The only threshold that shows a dependence on the ATMS incidence angle is th5, while some substantial differences are notable between GMI and ATMS. In particular, Test 4 is applied to a single channel (23.8 GHz V for GMI and QV for ATMS) with a different threshold depending on the near surface temperature. The values of the threshold have been set up empirically for both GMI and ATMS and have been tested for ATMS considering different scan angles separately. It is well known that the $\mathrm{V}$-pol emissivity at $53.1^{\circ}$ is always higher than the QV-pol emissivity at the same viewing angle (see Hewison and English 1999). Therefore, Test 4 is substantially different for GMI and ATMS. Moreover, QV emissivity shows a decrease with the incidence 

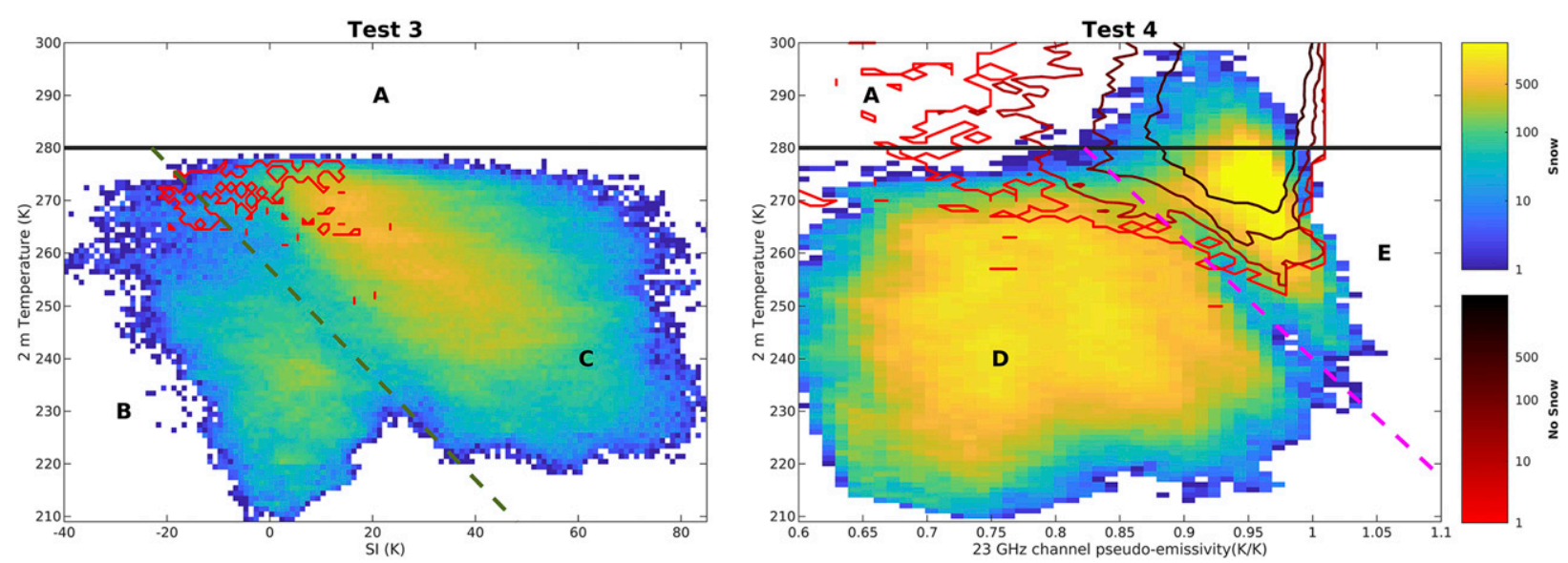

FIG. 3. Density scatterplot for ATMS snow-cover occurrences (upper-right color scale) for (left) $R_{\mathrm{LF}}>$ th2 and (right) $R_{\mathrm{LF}} \leq \mathrm{th} 2$. In each panel, two snow-cover clusters are identified: clusters B and C (corresponding to Polar Winter Snow and Deep Dry Snow, respectively), with the discriminant function of SI vs $T_{2 \mathrm{~m}}$ implemented for Test 3 (dark-green dashed line) are shown in the left panel. Clusters D and E (corresponding to Perennial Snow and "Thin Snow/snow-free land," respectively), with the discriminant function of 23-GHz pseudoemissivity $\left(\mathrm{TB}_{\mathrm{LF}} / T_{2 \mathrm{~m}}\right)$ vs $T_{2 \mathrm{~m}}$ implemented for Test 4 (pink dashed line) are shown in the right panel. The contours of the snow-free land occurrences are also shown, with the 1,10,100, and 500 isolines following the lower-right color scale. The letter A in both panels indicates the cluster of assumed snow-free pixels based on the $T_{2 \mathrm{~m}}>280 \mathrm{~K}$ criterion.

angle that is stronger for snow-covered than for snow-free land. Therefore, the ATMS Test 4, optimized for nadir-looking angles, works well also at off-nadir angles. The viewing angle is critical in Test 5 . In this case, Thin Snow is discriminated from snow-free land by testing the SI. The rationale here is that a thin layer of snow will produce a sensible volume scattering at $89 \mathrm{GHz}$ but not at $23 \mathrm{GHz}$, which will "sense" the soil below the thin snow layer. One result from the analysis of the viewing geometry dependence of ATMS in detecting snow cover is that the thickness of a snow layer producing enough volume scattering to be sensed depends on the zenith angle. In particular, a dependence from the optical pathlength has been found, which introduces a $1 /[\cos (\theta)]$ factor for ATMS. Therefore, th5 has been set to $3 \mathrm{~K} /[\cos (\theta)]$, which corresponds to $5 \mathrm{~K}$ for the $53.1^{\circ} \mathrm{GMI}$ zenith angle. This value corresponds to the threshold that has been independently determined for Test 5 for GMI.

\section{Results}

The validation dataset, considering AutoSnow as reference, has been used to assess the snow-cover detection capabilities of the algorithm both for GMI and for ATMS. Each radiometer pixel where AutoSnow snow-cover occurrence index is larger than 0.5 is considered as "snow pixel." The probability of detection (POD), false alarm ratio (FAR), and Heidke skill score (HSS) indices have been calculated. The validation dataset has been used to analyze the dependence of the snow-cover detection statistical scores on the environmental conditions, specifically, TPW, $T_{2 \mathrm{~m}}$, and surface elevation. The sensitivity of the algorithm detection skills to the presence of clouds has been analyzed using the CPR 2B-GEOPROF product cloud mask associated with each observation in the development dataset. The analysis dataset, based on SNODAS, has been used to study the specific characteristics of the two snow-cover classes identified in the CONUS domain and to verify the algorithm ability to distinguish between the two classes.

From a preliminary analysis, it has been observed that the GMI algorithm shows rare occurrences of false alarms over Sahara and part of the Arabian Peninsula. As a matter of fact, several studies have shown that sand deserts have an emissivity spectrum very similar to snow cover (or light precipitation; e.g., Grody and Weng 2008). To exclude this false detection of snow over desert, the sand desert areas have been identified using the same method described by Casella et al. (2015) and have been excluded from the analysis shown in the following sections.

\section{a. Snow-cover detection}

\section{1) DEPENDENCE ON CLOUD COVER AND ATMOSPHERIC HUMIDITY}

In this analysis two extreme cases of cloud cover have been considered: $0 \%$ and $100 \%$ over the ATMS/GMI pixel in the region observed by CPR. Since CPR observes just a very small fraction of the ATMS and GMI elliptical IFOV (i.e., a 1.4-km-wide swath across the IFOV), both cases will include some occurrences of partial cloud cover in the IFOV area not covered by the CPR track. However, the cloud cover statistics of the two cases will be very different: all the clear sky IFOV will be accounted in the $0 \%$ case and all the fully cloud covered IFOV will fall in the $100 \%$ case. To separate the effect of water vapor [analyzed in Fig. 4, and showing a strong impact on PESCA snow detection capabilities especially for TPW higher than $10 \mathrm{~mm}$ ] from the effect of clouds, the results are shown for dry conditions (TPW $<5 \mathrm{~mm}$ ). Both GMI and ATMS detection skills reported in Table 5 show that the presence of clouds does not affect the POD for ATMS (0.95). GMI shows a very small variation in the POD with and without clouds $(0.91$ and 0.95 , respectively). The false alarms are very low $(<0.03)$ and 

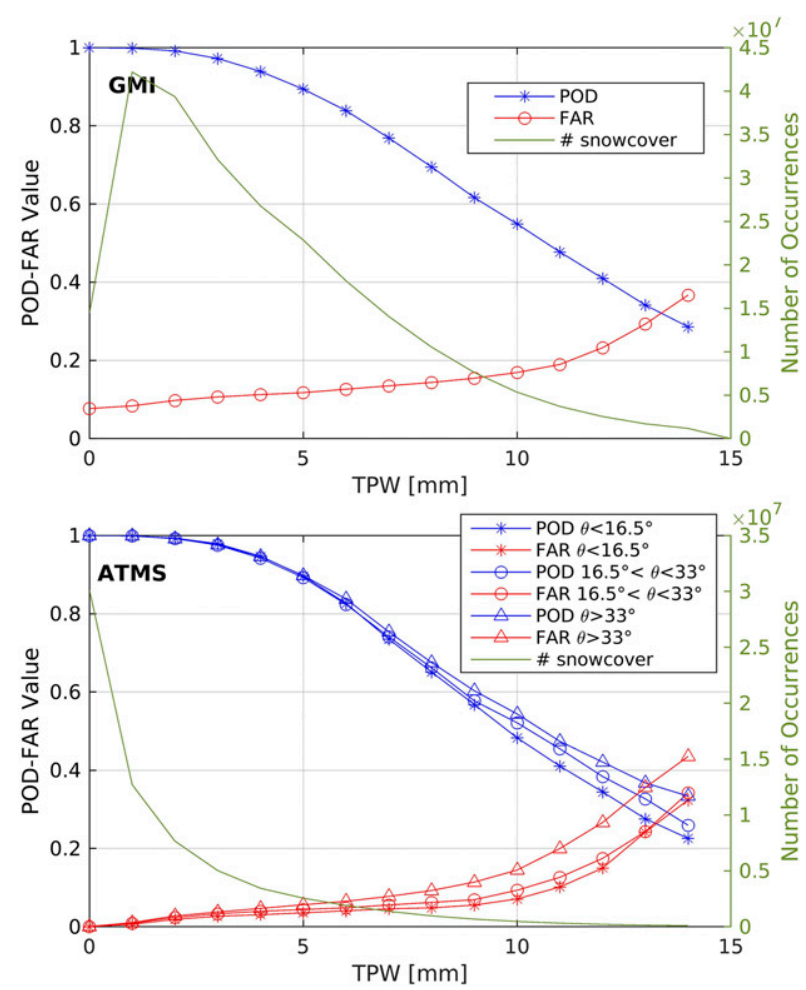

FIG. 4. POD (blue curve) and FAR (red curve) as a function of TPW for (top) GMI and (bottom) ATMS. The values of the mean POD and FAR for each 1-mm TPW bin are represented on the left axis. The right axis of each panel shows the number of AutoSnow snow-cover occurrences for each 1-mm TPW bin (green curve). For ATMS, there are three curves depending on the viewing angle.

show a very small variation with and without clouds. Overall, the detection capabilities of PESCA in the presence of clouds are still very robust. This is a fundamental result for the application of the algorithm independently of the cloud cover conditions at the time of the sensor overpass, also for snowfall retrieval.

Figure 4 shows the analysis of the influence of the atmospheric water vapor content (TPW) on the algorithm snowcover detection capabilities, tested on the validation dataset (AutoSnow, PMW). The figure shows the results in terms of POD and FAR for GMI and ATMS. For ATMS, the dependence of POD and FAR on the viewing angle is analyzed by grouping the results in three scan-angle categories. It is clear from Fig. 4 that the atmospheric water vapor strongly influences PESCA detection capabilities both for ATMS and GMI. POD decreases from almost 1 for very small values of TPW $(<3 \mathrm{~mm})$ to 0.9 for TPW around $5 \mathrm{~mm}$, and then it decreases almost linearly to 0.55 (0.45) for GMI (ATMS) for TPW around $10 \mathrm{~mm}$ (and to lower values as TPW increases). The FAR, on the other hand, increases with TPW, but it is always below 0.2 for both GMI and ATMS for TPW around $10 \mathrm{~mm}$. The influence of the scan angle on the ATMS results is also evident in Fig. 4. In particular, near-nadir angles show lower POD and FAR than off-nadir angles. Some differences between the ATMS and GMI detection capabilities can be noted.
TABLE 5. POD and FAR for GMI and ATMS snow-cover detection with and without cloud cover.

\begin{tabular}{lcccc}
\hline \hline & \multicolumn{2}{c}{ ATMS } & \multicolumn{2}{c}{ GMI } \\
\hline Cloud cover fraction & 0 & 1 & 0 & 1 \\
POD & 0.95 & 0.95 & 0.91 & 0.95 \\
FAR & 0.01 & 0.02 & 0.02 & 0.01 \\
\hline
\end{tabular}

In particular, for TPW $<10 \mathrm{~mm}$ the GMI algorithm tends to show higher values of FAR than ATMS, while for TPW $>$ $10 \mathrm{~mm}$ the GMI results are very consistent with the ones from ATMS at higher view angles. Some differences can be noted also for the AutoSnow snow-cover occurrences for each TPW bin in the two datasets (green lines in Fig. 4). This is due to the differences in the regions observed by GMI and ATMS (ATMS covers the polar regions while GMI orbits are limited to $67^{\circ} \mathrm{N} / \mathrm{S}$ ) and to the different number of snow-cover observations in the two datasets (see Table 3). The strong influence of TPW on the algorithm performance is due to the radiometric emission by the atmospheric water vapor that tends to mask the background surface signal, enhancing the TBs at all frequencies (in particular, at 23,31-37, and $89 \mathrm{GHz}$ ) and masking the snow surface volume scattering features associated with cold TBs. The TPW adversely affects the snow detection even in relatively dry conditions $(5-10 \mathrm{~mm})$ and compromises the snow detection when TPW is higher than $10 \mathrm{~mm}$. From these results, it is possible to define the upper working limit of both GMI and ATMS algorithms in terms of TPW, which is set to $10 \mathrm{~mm}$. Observations associated with TPW values higher than $10 \mathrm{~mm}$ have been removed from the datasets and from the analysis shown in the following sections. This selection excludes a relatively small fraction of the observations from the validation datasets: only 3.7\% snow-cover observations for the GMI dataset, and only $2.6 \%$ for ATMS.

The impact of water vapor emission and clouds have been addressed and considered with different approaches in previous studies on snow emissivity retrieval (e.g., Prigent et al. 2003; Cordisco et al. 2006; M20). It is worth noticing, however, that all approaches are applied only to conically scanning radiometers. M20 retrieve the full GMI 10-166-GHz emissivity vector using optimal estimation. The retrievals of the water vapor and surface states are performed simultaneously, while cloud- and precipitation-affected emissivities are screened. Our results show that the input variables and the thresholds used in PESCA for the detection and characterization of snow cover are not significantly influenced by the presence of clouds. The SI (i.e., $\mathrm{TB}_{23 \mathrm{~V}}-\mathrm{TB}_{89 \mathrm{~V}}$ for GMI) in particular, widely used in the literature for snow detection (Grody and Basist 1996), is one of the input parameters used for the detection of Thin Snow, which is the most critical (more subject to missed or false detection). The SI could be affected by the presence of clouds in different ways. Several authors have demonstrated the sensitivity of the $90 \mathrm{GHz}$ channels to the emission by supercooled cloud water (e.g., Kneifel et al. 2010; Panegrossi et al. 2017), which tends to increase the TBs. This effect compensates the cooling of the TBs due to the scattering by the falling snow. At $90 \mathrm{GHz}$ the cooling effect is mostly visible in presence 
of heavily rimed crystals (e.g., in convective mixed-phase clouds). Therefore, on one side the presence of liquid water over a snow background should decrease the SI, negatively impacting the algorithm snow detection capabilities. On the other side, convective mixed-phased clouds would increase the SI, similarly to snow cover, producing false alarms. The results shown in Table 5 can be attributed to two main reasons: first, in this test the algorithm is applied only over land in relatively cold $\left(T_{2 \mathrm{~m}}<280 \mathrm{~K}\right)$ and dry conditions (TPW $<5 \mathrm{~mm}$, lower than the PESCA TPW working limit) where mixed-phase convective clouds are apparently not so frequent (see also Milani et al. 2020); second the algorithm makes use of minimum thresholds for the SI (th3 in Test 3, and th5 in Test 5), which evidently are low enough not to be significantly affected by the TB warming effect due to (supercooled) cloud liquid water emission.

\section{2) DEPENDENCE ON SURFACE ELEVATION}

The presence of complex orography can influence the snowcover detection capabilities of microwave sensors. Grody and Basist (1996) mentioned that rocky cold background can easily be confused with snow cover. Moreover, the low spatial resolution, especially for ATMS, does not allow depicting the small-scale snow-cover variability that characterizes the orographic regions. In Fig. 5 the detection capabilities of the two algorithms are analyzed as a function of the IFOV mean surface elevation associated to each GMI and ATMS pixel in the validation dataset. In this analysis, the observations above $67^{\circ} \mathrm{N} / \mathrm{S}$ in the ATMS dataset have been excluded (for coherence with GMI, and to exclude the Antarctic and Greenland Plateaus), and only observations with TPW $<10 \mathrm{~mm}$ are considered [see section $4 \mathrm{a}(1)$ ]. The behavior of the three curves for ATMS and GMI shown in the two panels is quite similar, except for the lower population of the ATMS dataset, and for the slightly higher POD and FAR for GMI with respect to ATMS for surface elevation $>2500 \mathrm{~m}$. While the POD does not show a clear dependence on the pixel mean elevation, a significant increase of the FAR is found around $2500 \mathrm{~m}$ MSL, both for ATMS and GMI. This value is used as the upper working limit of the algorithm. This limit excludes from the validation dataset [already selected for TPW $<10 \mathrm{~mm}$, see section $4 \mathrm{a}(1)] 3.2 \%$ and $4 \%$ of snow-cover observations for GMI and ATMS, respectively. Despite this limit, a geographical analysis of the results shows that the main regions associated with false alarms are mountainous areas (with a mean elevation $<2500 \mathrm{~m}$ ), such as the Rocky Mountains in North America and the Mongolia region. In this region the false detections seem to be particularly problematic probably also because of the presence of the cold Gobi Desert.

\section{3) DEPENDENCE ON NEAR-SURFACE TEMPERATURE}

The influence of near-surface temperature $\left(T_{2 \mathrm{~m}}\right)$ on PESCA snow-cover detection capabilities is analyzed in Fig. 6. In this analysis, all observations with TPW $>10 \mathrm{~mm}$ or elevation $>$ $2500 \mathrm{~m}$ MSL (omitting the polar areas over $67^{\circ} \mathrm{N} / \mathrm{S}$ ) have been excluded. A strong dependence of POD and FAR on the temperature for $T_{2 \mathrm{~m}}>260 \mathrm{~K}$ is visible. For both radiometers, POD and FAR are respectively close to 1 and 0 for $T_{2 \mathrm{~m}}<265 \mathrm{~K}$.
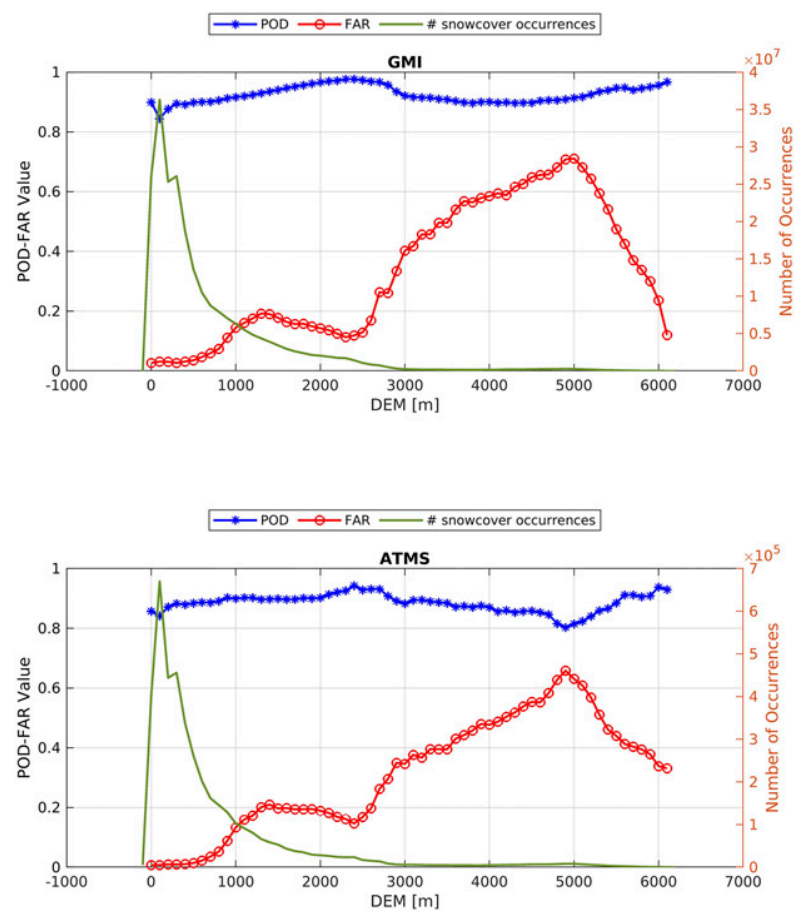

FIG. 5. POD (blue curve) and FAR (red curve) as a function of the mean surface elevation (derived from a DEM) associated with each observation (pixel) for (top) GMI and (bottom) ATMS. The values of the mean POD and FAR for each elevation bin are represented on the left axis. The right axis of each panel shows the number of AutoSnow snow-cover occurrences for each $100-\mathrm{m}$ elevation bin (green curve). Only latitudes $67^{\circ} \mathrm{S}$ and $67^{\circ} \mathrm{N}$ are considered.

Above this value the detection capabilities start to get worse, with POD (FAR) equal to $0.82(0.18)$ and $0.87(0.08)$ at $T$ around $270 \mathrm{~K}$, for GMI and ATMS respectively, and with a clear fall between 270 and $280 \mathrm{~K}$. The detection worsening at warm temperature is due to the impact of water vapor, to the occurrence of Thin (and/or wet) Snow in these conditions, and to the likelihood of missing scattered snow cover within the satellite IFOV (see section 4b). It is worth noticing in Fig. 6 the different distribution of the snow-cover observations (green curves) that is a consequence of the different areas covered by the two instruments. Figure 6 shows the results for three scanangle categories of ATMS; however, no significant influence of the scan angle can be appreciated.

\section{4) GENERAL DETECTION STATISTICS AND COMPARISON WITH A MACHINE-LEARNING MODEL}

Table 6 shows the general statistics for PESCA snow-cover detection for GMI and ATMS. ATMS results are presented as a function of the scan angle and separating the statistics over the whole globe from the one over the GPM coverage domain (i.e., within $67^{\circ} \mathrm{S} / \mathrm{N}$ ). It is clear from Table 6 that the scan angle has a small impact on the results, while the domain of application has a stronger impact. In comparing the results for GMI with the outer portion of ATMS swath (scan angles between $33^{\circ}$ and $52.8^{\circ}$ ) and for the same domain (first and last row of 

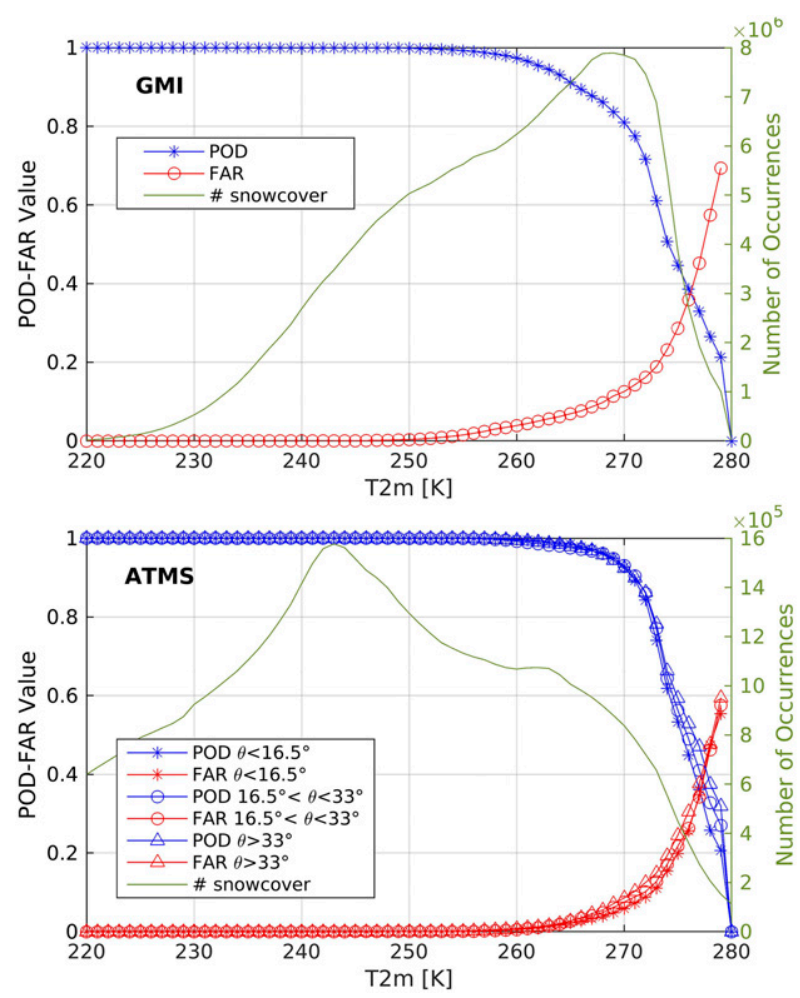

FIG. 6. POD (blue curve) and FAR (red curve) as a function of $T_{2 \mathrm{~m}}$ associated with each observation (pixel) for (top) GMI and (bottom) ATMS. The values of the mean POD and FAR for each $1-\mathrm{K} T_{2 \mathrm{~m}}$ bin are represented on the left axis. The right axis of each panel shows the number of AutoSnow snow-cover occurrences for each $T_{2 \mathrm{~m}}$ bin (green curve). For ATMS, there are three curves depending on the viewing angle.

Table 6), it is seen that the results are very similar, with a POD of 0.92 (for both GMI and ATMS) and a FAR of 0.08 for GMI and 0.07 for ATMS. Since the algorithms are very efficient in the low temperature range, the application of PESCA to ATMS over the global area (including polar regions) results in significantly improved statistics.

To compare PESCA with a supervised classification method, Table 6 reports also the results obtained from an automated machine-learning algorithm, using the validation dataset for GMI (labeled as GMI RB). Table 6 reports also the Heidke skill score (HSS) and the accuracy (ACC). Both indices measure the skill in detecting snow cover; while ACC measure the fraction of correct prediction, HSS is relative to the skill of a random prediction. In comparing PESCA GMI and ATMS for the higher view angles and over the same region, it is seen that ACC is consistent (0.88) while the PESCAGMI HSS is higher than ATMS (0.69 and 0.65, respectively). In this experiment the development dataset has been used to train a RobustBoost algorithm using the same GMI input used in PESCA GMI. RobustBoost (Freund 2009) is a version of the gradient boosting approach that assumes a "label noise," that in our case is the uncertainty of the reference snow-cover dataset. The assumed label noise has been tuned varying it from $1 \%$ to $70 \%$. The final algorithm that gave the best results (in terms of accuracy during the test phase) was the one associated with a $10 \%$ uncertainty. This result indicates that the reference snow cover in the training and validation datasets is affected by an uncertainty of about $10 \%$. This uncertainty is due to errors of AutoSnow product and to the discrepancies between the instantaneous MW TBs and the daily product. The RobustBoost algorithm is associated with an accuracy of $89 \%$, very close to the ideal limit of $90 \%$ due to the assumed label noise $(10 \%)$. Notice that the PESCA algorithm accuracy is very close to the RobustBoost accuracy ( $88 \%$ for GMI and $88 \%-89 \%$ for ATMS applied to the GPM area), confirming the effectiveness of the procedure followed in PESCA design phase and in the evaluation of the thresholds for the different tests.

\section{b. Snow-cover categories}

The near surface temperature $\left(T_{2 \mathrm{~m}}\right)$ has been used to analyze if the different snow-cover classes identified by the algorithm effectively correspond to different temperature regimes. Figure 7 shows the probability density functions (PDFs) of the $T_{2 \mathrm{~m}}$ associated to the four ATMS snow classes. The Polar Winter Snow is typically found at very low temperatures (mostly below $240 \mathrm{~K}$ ), while Deep Dry Snow is found at moderately cold temperatures (240-275 K). Thin Snow class is predominantly found at $T_{2 \mathrm{~m}}$ near and above $270 \mathrm{~K}$. It is worth noting that snow pixels (according to AutoSnow) classified by PESCA as snow-free land (misses) are always associated to $T_{2 \mathrm{~m}}$ above $270 \mathrm{~K}$. Moreover, Table 7 reports the different percentage of hits and FAR values for each class, showing that the majority of false alarms are classified as Thin Snow. Notice, however, that the warm conditions, more frequent for Thin Snow, are also the ones where the reference daily dataset could

TABLE 6. Summary of PESCA snow-cover detection statistics.

\begin{tabular}{|c|c|c|c|c|c|c|}
\hline & Domain & Zenith angle & POD & FAR & HSS & $\mathrm{ACC}$ \\
\hline GMI PESCA & GPM & $53^{\circ}$ & 0.92 & 0.08 & 0.69 & 0.88 \\
\hline GMI RB & GPM & $53^{\circ}$ & 0.94 & 0.08 & 0.71 & 0.89 \\
\hline ATMS PESCA & Global & $0^{\circ}-16.5^{\circ}$ & 0.98 & 0.01 & 0.72 & 0.97 \\
\hline ATMS PESCA & Global & $16.5^{\circ}-33^{\circ}$ & 0.98 & 0.01 & 0.71 & 0.96 \\
\hline ATMS PESCA & Global & $33^{\circ}-52.8^{\circ}$ & 0.97 & 0.02 & 0.70 & 0.96 \\
\hline ATMS PESCA & GPM & $0^{\circ}-16.5^{\circ}$ & 0.91 & 0.05 & 0.67 & 0.89 \\
\hline ATMS PESCA & GPM & $16.5^{\circ}-33^{\circ}$ & 0.91 & 0.06 & 0.66 & 0.88 \\
\hline ATMS PESCA & GPM & $33^{\circ}-52.8^{\circ}$ & 0.92 & 0.07 & 0.65 & 0.88 \\
\hline
\end{tabular}




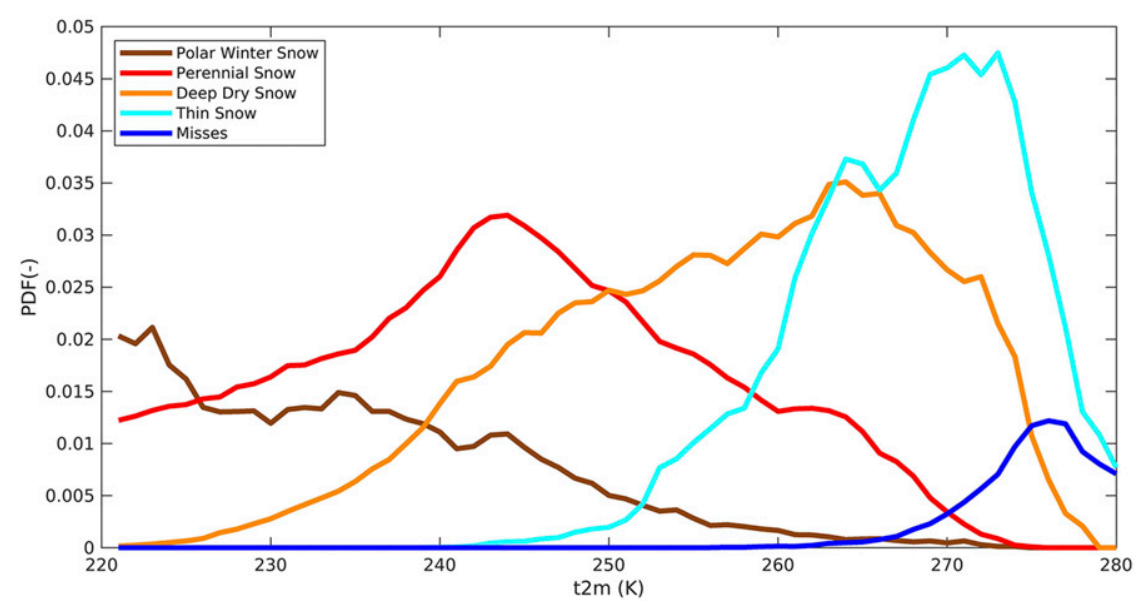

FIG. 7. PDFs of $T_{2 \mathrm{~m}}$ for the different ATMS snow-cover categories: Polar Winter Snow, Perennial Snow, Deep Dry Snow, and Thin Snow. The PDF of missed cases (AutoSnow snow pixels classified as snow-free land by the ATMS algorithm) is also shown.

be subject to rapid changes of the snow-cover status due to snow melting.

\section{1) ANALYSIS OF SNOW CATEGORIZATION OVER CONUS}

The physical characteristics of the ATMS and GMI snowcover classes have been analyzed using the SNODAS snowcover properties over the CONUS region stored in the analysis dataset. In particular, the SD, as well as the snow precipitation and melted snow mass in the last $24 \mathrm{~h}$ have been considered. The Perennial Snow and Polar Winter Snow classes are underrepresented in the CONUS domain $(0.6 \%$ of occurrences for ATMS, 2\% for GMI), therefore only Deep Dry Snow and Thin Snow are analyzed, as well as the characteristics of the missed snow (misses).

The PDFs of the SNODAS SD for Deep Dry Snow, Thin Snow, and misses are shown in Fig. 8 for GMI and ATMS. The three PDFs show distinct features. The misses are characterized by very low values of SD, the Thin Snow class is mostly associated with SD less than $0.2 \mathrm{~m}$, while the Deep Dry Snow is characterized by a large range of $\mathrm{SD}$, up to more than $1 \mathrm{~m}$, including also moderate snow depth (less than $0.1 \mathrm{~m}$ ). When comparing the PDFs of the three classes obtained for GMI and ATMS, it is worth noting important differences: both for the Deep Dry Snow and Thin Snow classes the occurrences for very low snow depth values (below 0.1 and $0.01 \mathrm{~m}$ for the two classes) are higher for GMI than for ATMS. The differences in the distribution can be partially attributed to the different characteristics of the two radiometers, mainly the different viewing geometry and spatial resolution. It is evident, however, that some inconsistencies between the GMI and the ATMS algorithms remain even for similar viewing angles.

A clear dependence of the classification on SNODAS fresh snow (due to snow precipitation or snowmelt mass in the previous $24 \mathrm{~h}$ ) has not been observed. This is an indication that the algorithm is not able to distinguish snow-cover radiative properties related to the presence of wet snow, while fresh snow is likely included in the other classes (either Deep Dry Snow or Thin Snow).

\section{2) TEMPORAL AND GEOGRAPHICAL GLOBAL SNOW-COVER DISTRIBUTION}

In this section the monthly and geographical variability of the different snow categories identified for ATMS and GMI, as well as their relative contribution to the total snow-cover occurrences identified with each sensor, are analyzed.

Figure 9 reports the monthly snow-cover frequency for the different snow classes for GMI and ATMS in the year 2015. For each class, the monthly snow frequency is obtained dividing the number of monthly occurrences for a given class by the total number of occurrences of the same snow class in the whole year. Therefore, in Fig. 9 it is possible to analyze the seasonal variability of each class. There is a substantial coherence between the snow classes' seasonality for the two radiometers for Deep Dry Snow and Thin Snow. In particular, it is evident

TABLE 7. HITS percentage and FAR values for each snow-cover class identified.

\begin{tabular}{|c|c|c|c|c|c|c|}
\hline & \multicolumn{2}{|c|}{ ATMS } & \multicolumn{2}{|c|}{ ATMS (GMI belt) } & \multicolumn{2}{|c|}{ GMI } \\
\hline & $\%$ hits & FAR for class & $\%$ hits & FAR for class & $\%$ hits & FAR for class \\
\hline Perennial Snow & 63 & 0.0006 & 2 & 0.9 & 10 & 0.01 \\
\hline Polar Winter Snow & 9 & 0.0008 & - & 0 & - & - \\
\hline Deep Dry Snow & 21 & 0.004 & 69 & 0.2 & 83 & 0.04 \\
\hline Thin Snow & 7 & 0.2 & 29 & 0.3 & 7 & 0.27 \\
\hline
\end{tabular}



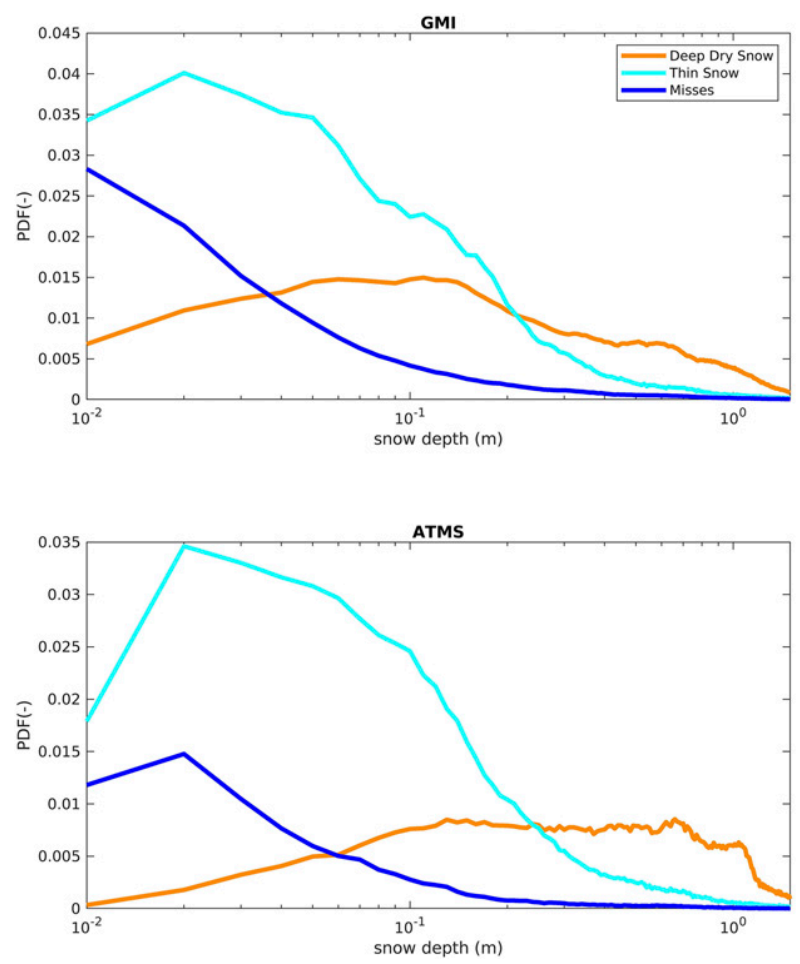

FIG. 8. PDFs of the SNODAS snow depth for the (top) GMI and (bottom) ATMS main snow-cover categories over CONUS (Deep Dry Snow and Thin Snow). The PDF of the misses is also shown.

that the Deep Dry Snow class is mostly found during the winter period, with largest occurrence in January and February than in December. A linear decrease during spring until the minimum is reached in the summer months, and a linear increase during the fall until early winter are visible. The Thin Snow class has highest frequency in autumn and early winter and lower frequency in late winter and spring. GMI shows a peak during the spring that can be attributed to the fact that its higher spatial resolution allows one to identify small regions of shallow snow that are not detected with ATMS. It is worth noting that for ATMS the high latitudes contribute to the nonzero frequency values found for both Thin and Deep Dry Snow during most of the summer, with a minimum in June for Deep Dry Snow and in August for Thin Snow. For ATMS, the Perennial Snow class does not show large variability during the year because it is dominated by the occurrence at high latitudes (mostly over the Greenland Plateau as shown in Fig. 10). It shows larger occurrence between January and June than between July and December. On the other hand, GMI, which covers only partially the high latitudes $\left(>67^{\circ} \mathrm{N}\right)$ and only the southern part of Greenland, shows a partially seasonal behavior of Perennial Snow due to the larger relative contribution of lower latitudes ("no-Greenland" curve in the top panel), and to the larger variability of snow conditions in the southern coast of Greenland relative to the inner plateau. The Polar Winter Snow class, detected only by ATMS, presents a strong seasonal behavior with largest frequency in late fall and early winter. Note, however, that the total number of
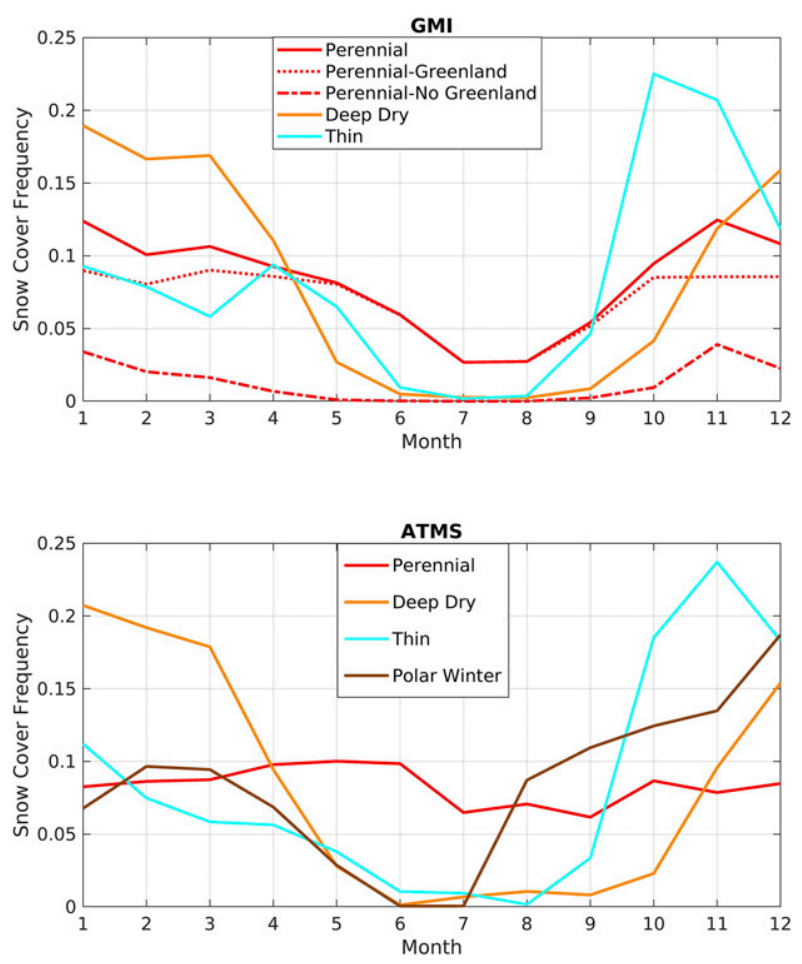

FIG. 9. Monthly snow frequency for the (top) three GMI and (bottom) four ATMS snow categories in the Northern Hemisphere. The snow frequency is obtained by dividing the number of monthly occurrences for a given class by the total number of occurrences of the same snow class in the whole year.

occurrences for Polar Winter Snow in the Northern Hemisphere is very low (1.3\% of total occurrences).

Figure 10 reports the global maps at $1^{\circ} \times 1^{\circ}$ resolution of snow-cover occurrence (in percentage) for ATMS and GMI for the year 2015. For each radiometer the occurrence percentage is computed as the number of snow occurrences in each $1^{\circ} \times 1^{\circ}$ grid box for the snow category shown in each panel, divided by the total number of snow occurrences in the same grid box. In all GMI and ATMS panels the coast boundaries (larger for ATMS than for GMI) are not shown. The map of the total number of snow occurrences for AutoSnow (in the ATMS validation dataset) is also shown as reference (in the bottom-left panel). The Perennial Snow class is predominant in the polar regions (mainly in the Greenland and Antarctic Plateaus as shown in the ATMS maps) and much less frequent in the other parts of Earth, while Deep Dry Snow and Thin Snow classes are the most frequent categories, especially at the mid-to-high latitudes. These are the categories more subject to seasonal and diurnal variability at midlatitudes, therefore at high latitudes (and in the winter season, not shown) there is more consistency between the two radiometers. The Winter Polar Snow class is found only by ATMS over the inner Antarctic and Greenland Plateaus and in the northern coastal areas of Greenland.

From the comparison of the left and right panels, it is possible to observe a substantial coherence at the high latitudes, 
GMI

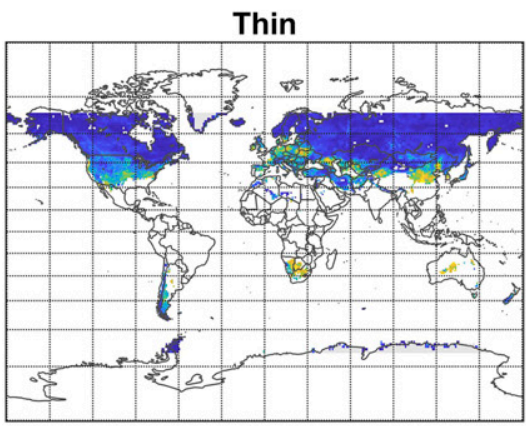

Deep Dry

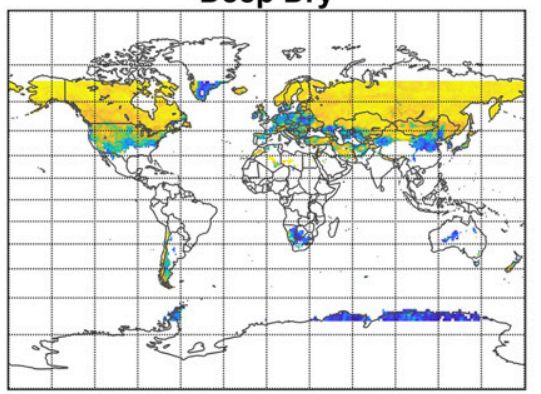

Perennial

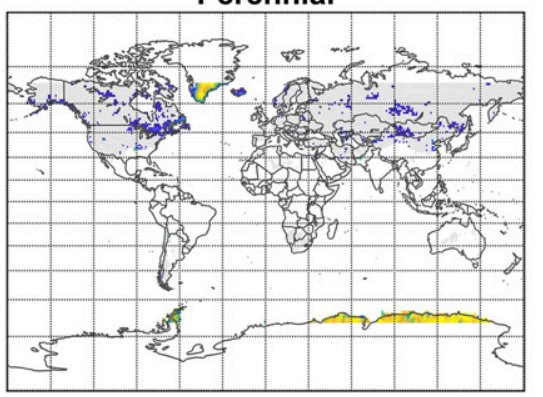

AutoSnow Total Occurrences

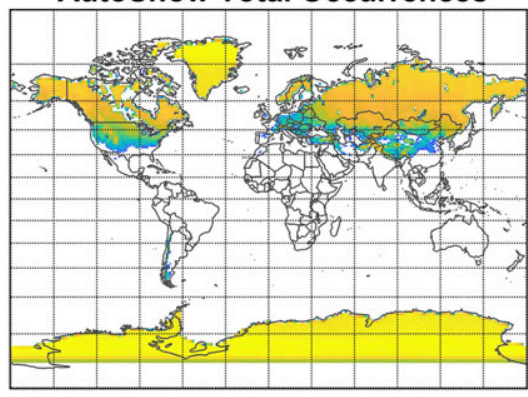

ATMS

Thin
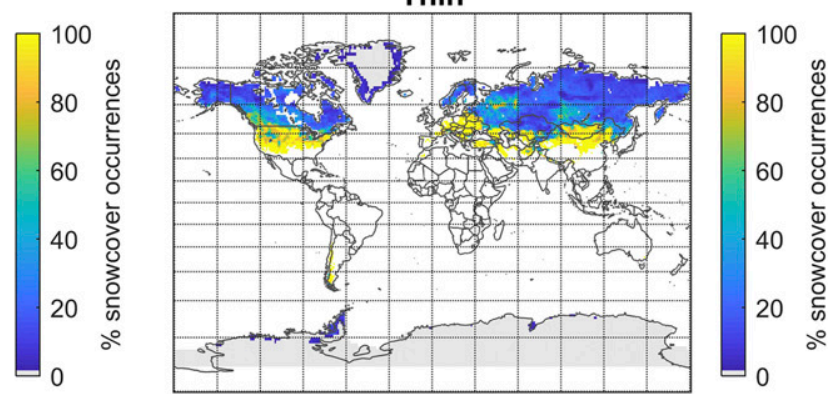

Deep Dry
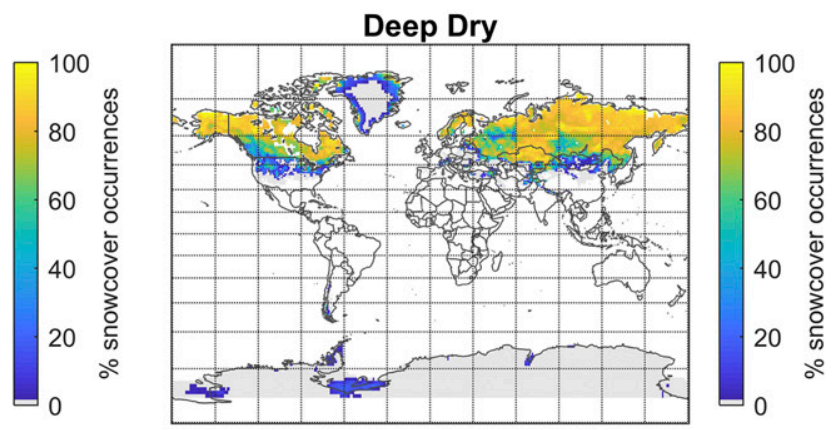

Perennial
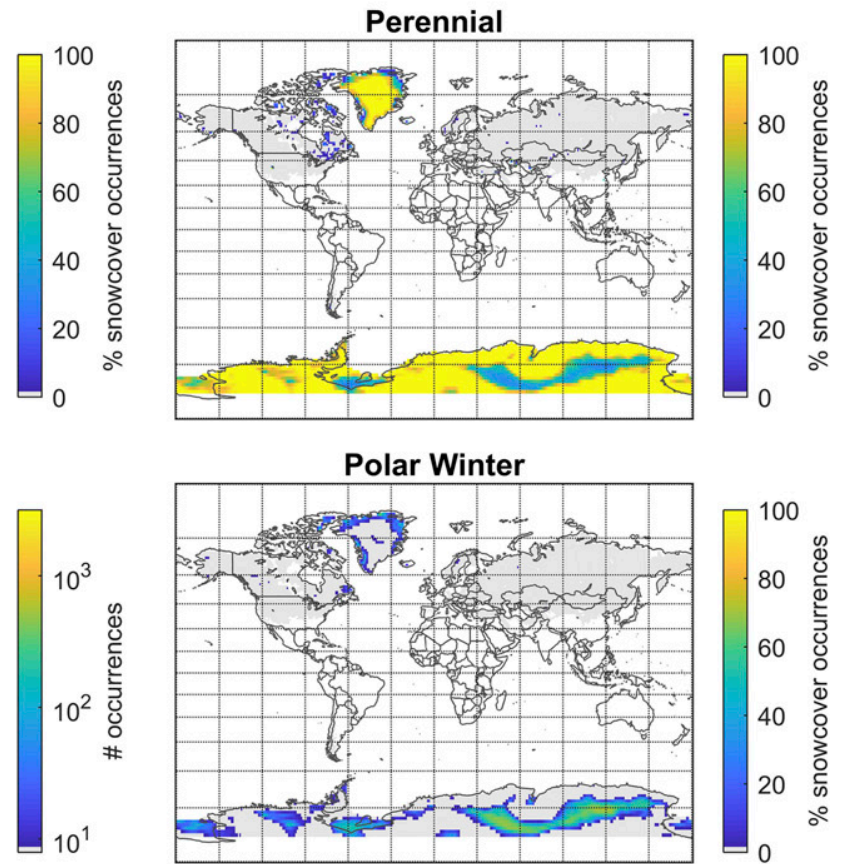

Polar Winter

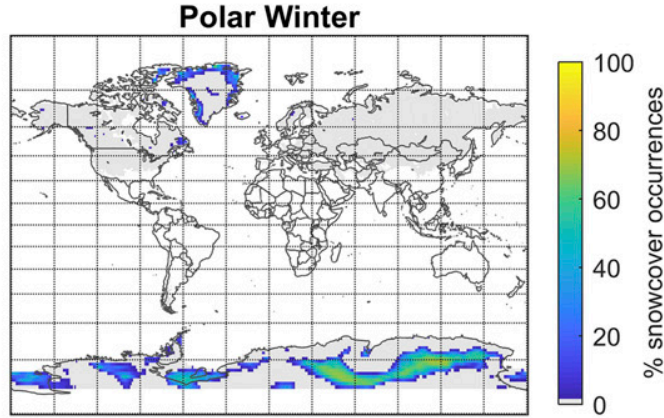

FIG. 10. Global maps at $1^{\circ} \times 1^{\circ}$ resolution of snow-cover occurrences (in percentage) for each snow category for (left) GMI and (right) ATMS classifier for 2015. In each panel, the percentage is computed by dividing the number of snow occurrences for the shown snow category by the total number of snow occurrences (either for GMI or ATMS) in each $1^{\circ} \times 1^{\circ}$ grid box. For ATMS, the Polar Winter Snow is also shown. The map on the bottom left shows the total number of snow occurrences for AutoSnow in the latitude region covered by ATMS.

especially for Perennial Snow, between the two radiometers (although more scattered occurrences are visible at lower latitudes for GMI). However, important differences both in the occurrence and in the geographical distribution of Deep Dry
Snow and Thin Snow are evident between the two radiometers. For both radiometers the Thin Snow and Deep Dry Snow are complementary to each other. There is larger occurrence of Deep Dry Snow at the expenses of Thin Snow for GMI at 
midlatitudes, while the opposite occurs for ATMS. This can be partially explained by the different spatial resolution of the two radiometers. A uniform snow-cover area may appear as Thin Snow $\left(R_{\mathrm{LF}}<1.01\right)$ for ATMS (because of the larger IFOV), while GMI may be able to better capture the Deep Dry Snow signal (with $R_{\mathrm{LF}}>1.01$ ). On the other hand, GMI shows larger snow occurrence of Deep Dry and Thin Snow than ATMS in areas with complex orography (e.g., Southern America, New Zealand), or in general where the snow may be subject to more diurnal variability and spatial inhomogeneity and where the occurrence of scattered shallow snow is more likely. In these areas, GMI, which is less affected by a nonuniform beam filling effect (NUBF) than ATMS, shows a better agreement with the AutoSnow occurrence map. Moreover, the GMI, which is not sun synchronous, is able to better capture the diurnal variability of snow cover.

\section{Analysis of snow-cover spectral signatures}

The goal of this section is to analyze the emissivity spectra for all GMI channels for the different snow-cover classes identified by the algorithm, including the higher frequencies ( $>90 \mathrm{GHz}$ ), which are more sensitive to the scattering by cloud ice in snowfall conditions. The GMI emissivities retrieved as described in M20 (and available from meso.gsfc.nasa.gov), for the dry snow categories (i.e., Deep Dry Snow, Perennial Snow, and Polar Winter Snow) have been analyzed in specific environmental conditions: 1) cloud-free conditions (based on CPR cloud mask, considering only observations (IFOV) with cloud fraction $<0.2$ ); 2) extremely low TPW (between 0.1 and $1 \mathrm{~mm}$ ) to minimize any eventual residual effect of water vapor on the retrieved emissivities; and 3) relatively cold $\mathrm{T}_{2 \mathrm{~m}}(250-260 \mathrm{~K})$ to get a sufficiently large population of each considered class. Figure 11 shows the emissivity spectra for the V-pol and H-pol channels for GMI, and the polarization signal, i.e., the emissivity difference between GMI V and $\mathrm{H}$ polarization channels. The panels show for each snow category the median emissivity (50th percentile) and the 25th and 75th percentiles for the different channels ( $x$ axis). It is clear from Fig. 11 that the three dry snow classes show very distinct spectral signatures and polarization properties. Characteristic features for the different classes at lower frequencies $(\leq 90 \mathrm{GHz})$ are clearly identified: 1) increase (decrease) of emissivity with increasing frequencies for Perennial Snow (Deep Dry Snow); 2) larger polarization signal for Perennial Snow than for Deep Dry Snow. The spectral signature above $90 \mathrm{GHz}$ also shows distinctive features: the emissivity at 89 and $166 \mathrm{GHz}$ is significantly different between the Deep Dry Snow and Perennial Snow classes, particularly for GMI V-pol. The emissivities at $183 \mathrm{GHz}$ are not shown, because these channels are affected by large uncertainties, due to the use of modelbased water vapor profiles (from MERRA) for the emissivity retrieval (M20).

Figure 12 shows a similar analysis, for the same environmental conditions of Fig. 11, on ATMS pseudoemissivity spectra, calculated as the TBs divided by the skin temperature. It is worth noticing that even with a rough approximation the emissivity spectra show distinct behaviors for each snow class.
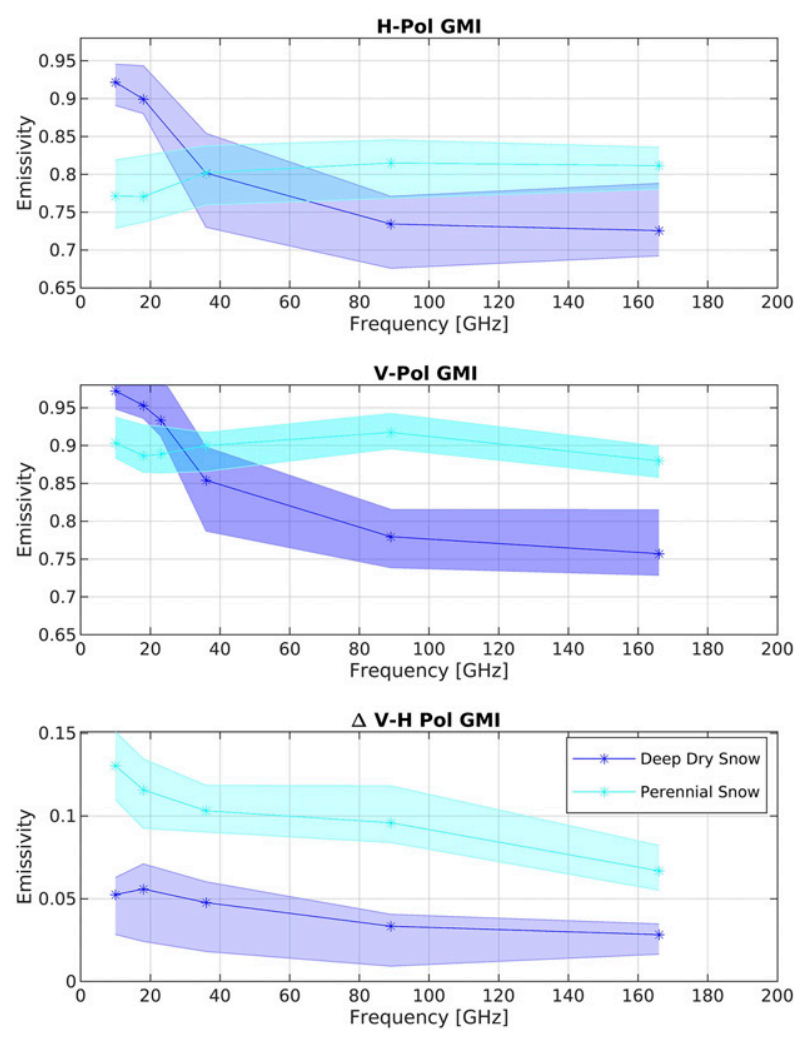

FIG. 11. Emissivity spectrum from M20 for GMI for Deep Dry Snow and Perennial Snow for (a) H-pol channels, (b) V-pol channels, and the (c) polarization difference. The median pseudoemissivity value (50th percentile) is shown as a continuous line, and the 25 th and 75 th percentiles are shown as shaded areas.

A similar analysis has been carried out for the Thin Snow found in warmer conditions, to compare it with the snowfree land class, and with misses (GMI observations where AutoSnow reports snow that is not detected by PESCA) (Fig. 13). Also in this case, the analysis is restricted to the observations without cloud cover (from CPR cloud mask), and to environmental conditions compatible with these snow classes ( $T_{2 \mathrm{~m}}$ between 270 and $280 \mathrm{~K}$ and TPW between 1 and $8 \mathrm{~mm}$ ). Figure 13 shows the emissivity spectra for GMI (from M20). It is worth noting that misses and snow-free land classes show a very similar spectra and polarization signal at all frequencies. At low frequency the Thin Snow class is very similar to the other two, while a marked difference is evident at $88-166 \mathrm{GHz}$.

The snow-cover categories identified in PESCA can be related to the snow classes found in M20 based on their GMI monthly surface emissivity maps: Perennial snow corresponds to snow cluster 1-2, while Deep Dry Snow to cluster 9-10 [observed also by Hewison and English (1999) and called Deep Dry Snow], while there is no correspondence in M20 for Polar Winter Snow, since GMI does not observe the internal regions of Antarctica and Greenland. The Thin Snow class may correspond to the ephemeral snow class as defined by M20 (even if some differences can be 


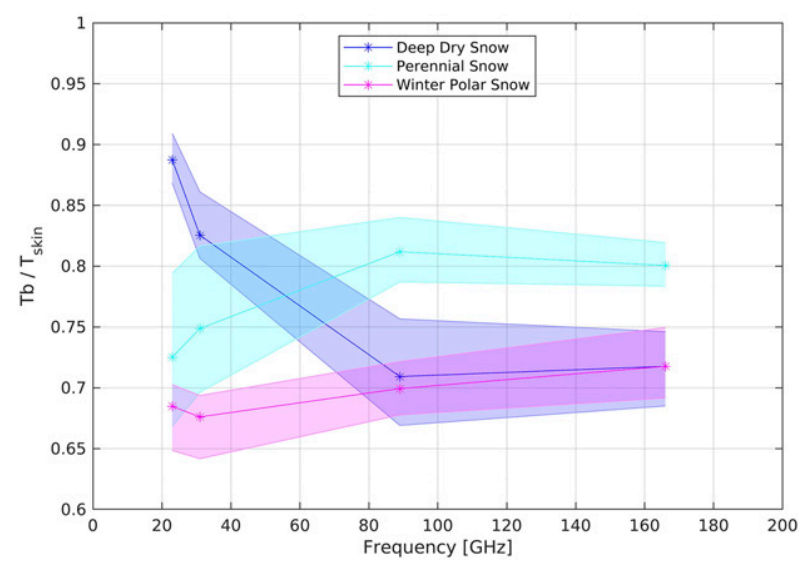

FIG. 12. Pseudoemissivity spectrum for ATMS for Deep Dry Snow and Perennial Snow. The median pseudoemissivity value (50th percentile) is shown as a continuous line, and the 25 th and 75 th percentiles are shown as shaded areas.

noticed as the relatively strong polarization of the emissivity around $37 \mathrm{GHz}$ ).

\section{Conclusions}

Several recent studies evidence how it is fundamental to be able to account for the dynamic background surface conditions in the satellite precipitation retrieval process and to adopt a method that takes into account the status of the surface at the time of the overpass. This is even more critical for snowfall detection and retrieval often occurring over a highly variable snow-covered background surface. Snow mantle shows a strongly variable spectrum of emissivity when observed in the MW. This variability is tight to the physical characteristics of the snow mantle layers.

This paper describes the new Passive Microwave Empirical Frozen Surface Classification Algorithm developed for the detection and characterization of the frozen background surface using passive microwave satellite measurements, with the aim of supporting snowfall detection and retrieval over land. The developed method is based on the exploitation of the lower-frequency channels $(<90 \mathrm{GHz})$ that are common to most microwave radiometers. PESCA consists of a single decision tree developed using an empirical method to define criteria and thresholds to identify different snow categories. The algorithm is simple and fast (to ease its implementation in a snowfall retrieval algorithm) and exploits known input parameters built upon the multichannel microwave brightness temperature response to snow-cover physical conditions, with very limited use of ancillary model inputs. PESCA is designed to allow for a deep understanding of the processes involved in the snow-cover detection and classification. Comparison with a machine-learning model (RobustBoost), and the good quality and robustness of the results obtained, confirm its good performance for snow-cover identification. The results shown demonstrate that the PESCA approach can be applied to both conically scanning (GMI) and cross-track-scanning (ATMS) radiometers equipped with frequency channels in the range of
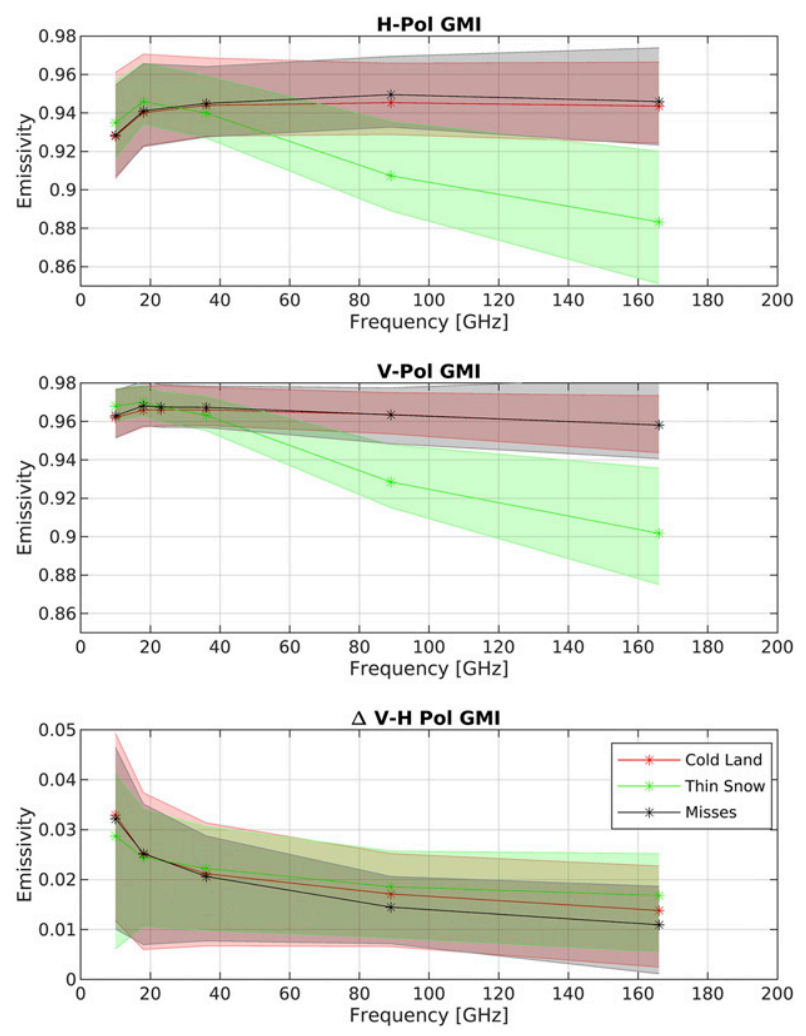

FIG. 13. Emissivity spectrum from M20 for GMI for Thin Snow and snow-free land, and misses (pixels where GMI fails in detecting snow) for (a) H-pol channels, (b) V-pol channels, and the (c) polarization difference. The median pseudoemissivity value (50th percentile) is shown as a continuous line, and the 25 th and 75 th percentiles are shown as shaded areas.

23-90 GHz. It is very efficient in the detection and characterizing snow cover in dry conditions, and its working limits have been defined as TPW $<10 \mathrm{~mm}, T_{2 \mathrm{~m}}<280 \mathrm{~K}$, and mean surface elevation $<2500 \mathrm{~m}$. The presence of clouds does not seem to significantly influence the algorithm performance. The differences in the global distribution of PESCA snow categories (Thin Snow, Deep Dry Snow, Perennial Snow, and Polar Winter Snow) between the GMI and ATMS can be related for the most part to their different viewing geometry, spatial resolution, and temporal sampling.

PESCA has been tuned to optimally categorize the emissivity spectrum observed by a specific radiometer, with its own sensing capabilities, and viewing geometry, in order to use this information in the precipitation retrievals. Since GMI and ATMS may have a different spectral signature for the same area, the classification obtained with PESCA is not perfectly coherent for the two instruments, especially in conditions where NUBF effects are more significant or when the snow layer is subject to more variability. The identified snow-cover classes, however, tend to correspond to distinct physical (i.e., $\mathrm{SD}$ and $T_{2 \mathrm{~m}}$ ) and radiometric features.

The main purpose of PESCA is the identification and characterization of the snow cover ancillary to snowfall detection and retrieval. The spectral signatures of the different snow 
classes identified at the time of the overpass appear to be different also for the high-frequency channels, indicating great potential for snowfall retrieval, especially in dry conditions.

The method can be easily implemented in operational and research algorithm for snowfall retrieval. Other surface-focused applications could benefit from the use of the PESCA approach, including retrieval of SWE and snow depth and characterization of freeze and thaw.

Possible future development of this algorithm will include the extension of a similar approach for the classification of sea ice (the algorithm is already developed and is being validated), and the application of PESCA to other MW radiometers in the GPM constellation. In particular, the ATMS algorithm can be used as a prototype for the cross-track-scanning radiometers [e.g., EUMETSAT Polar System Second Generation (EPS-SG) Microwave Sounder (MWS)] and the GMI algorithm can be used as a prototype for the conically scanning radiometers [SSM/I, SSMIS, AMSR-E, AMSR-2, and EPS-SG Microwave Imager (MWI)].

Acknowledgments. This work was funded by the RainCast study (ESA Contract 4000125959/18/NL/NA; Principal Investigator Prof. Alessandro Battaglia of the University of Leicester) and by the EUMETSAT Satellite Application Facility for Operational Hydrology and Water management (H SAF) Third Continuous and Operations Phase (CDOP-3). Author Andrea Camplani is supported by the Ph.D. program in Infrastructures, Transport Systems and Geomatics at the Department of Civil, Constructional, and Environmental Engineering at Sapienza University of Rome. The PMM Research Program is acknowledged for supporting H SAF and GPM scientific collaboration through the approval of the no-cost proposal "H SAF and GPM: Precipitation algorithm development and validation activity." The authors express their sincere gratitude to Joe Turk (NASA JPL) for developing and sharing the 2B-CSATGPM dataset used in this study and for the coordination activity in the PMM Land surface Working Group and to Joseph Munchak for sharing the GMI emissivity database in M20. Mark Kulie, Lisa Milani, and Alessandro Battaglia are warmly acknowledged for their useful interactions and discussions.

Data availability statement. For this study, the 1C-R-GMI, 1C-ATMS products (TBs) and the 2B-CSATGPM (CloudSatGPM coincidences) product have been used. These datasets are freely available through the NASA PPS data archive (https:// storm.pps.eosdis.nasa.gov/storm/). The SNODAS and AutoSnow datasets are available online from the National Weather Service Snow Analysis (https://www.nohrsc.noaa.gov/nsa/). ECMWF ERA5 data are available from the Climate Data Store (cds.climate. copernicus.eu; https://doi.org/10.24381/cds.adbb2d47).

\section{REFERENCES}

Amlien, J., 2008: Remote sensing of snow with passive microwave radiometers: A review of current algorithms. Norsk Regnesentral Rep. 1019, 52 pp.

Arons, E., and S. Colbeck, 1995: Geometry of heat and mass transfer in dry snow: A review of theory and experiment. Rev. Geophys., 33, 463-493, https://doi.org/10.1029/95RG02073.
Bennartz, R., and G. W. Petty, 2001: The sensitivity of microwave remote sensing observations of precipitation to ice particle size distributions. J. Appl. Meteor., 40, 345-364, https://doi.org/ 10.1175/1520-0450(2001)040<0345:TSOMRS > 2.0.CO;2.

- , and P. Bauer, 2003: Sensitivity of microwave radiances at 85-183 GHz to precipitating ice particles. Radio Sci., 38, 8075, https://doi.org/10.1029/2002RS002626.

—, F. Fell, C. Pettersen, M. D. Shupe, and D. Schuettemeyer, 2019: Spatial and temporal variability of snowfall over Greenland from CloudSat observations. Atmos. Chem. Phys., 19, 8101-8121, https://doi.org/10.5194/acp-19-8101-2019.

Berg, W., and Coauthors, 2016: Intercalibration of the GPM microwave radiometer constellation. J. Atmos. Oceanic Technol., 33, 2639-2654, https://doi.org/10.1175/JTECH-D-16-0100.1.

Carroll, T., D. Cline, C. Olheiser, A. Rost, A. Nilsson, G. Fall, C. Bovitz, and L. Li, 2006: NOAA's national snow analyses. Proc. 74th Annual Meeting of the Western Snow Conf., Las Cruces, NM, Western Snow Conference, 2-14.

Casella, D., G. Panegrossi, P. Sanò, L. Milani, M. Petracca, and S. Dietrich, 2015: A novel algorithm for detection of precipitation in tropical regions using PMW radiometers. Atmos. Meas. Tech., 8, 1217-1232, https://doi.org/10.5194/amt-8-12172015.

,,--- A. C. Marra, S. Dietrich, B. T. Johnson, and M. S. Kulie, 2017: Evaluation of the GPM-DPR snowfall detection capability: Comparison with CloudSat-CPR. Atmos. Res., 197, 64-75, https://doi.org/10.1016/j.atmosres.2017.06.018.

Chang, A. T. C., J. L. Foster, and D. K. Hall, 1987: Nimbus-7 SMMR derived global snow cover parameters. Ann. Glaciol., 9, 39-44, https://doi.org/10.1017/S0260305500200736.

Che, T., X. Li, R. Jin, R. Armstrong, and T. Zhang, 2008: Snow depth derived from passive microwave remote sensing data in China. Ann. Glaciol., 49, 145-154, https://doi.org/10.3189/ 172756408787814690 .

Chen, S., and Coauthors, 2016: Comparison of snowfall estimates from the NASA CloudSat cloud profiling radar and NOAA/NSSL multi-radar multi-sensor system. J. Hydrol., 541, 862-872, https:// doi.org/10.1016/j.jhydrol.2016.07.047.

Clifford, D., 2010: Global estimates of snow water equivalent from passive microwave instruments: History, challenges and future developments. Int. J. Remote Sens., 31, 3707-3726, https:// doi.org/10.1080/01431161.2010.483482.

Clow, D. W., L. Nanus, K. L. Verdin, and J. Schmidt, 2012: Evaluation of SNODAS snow depth and snow water equivalent estimates for the Colorado Rocky Mountains, USA. Hydrol. Processes, 26, 2583-2591, https://doi.org/10.1002/hyp.9385.

Colbeck, S. C., 1976: An analysis of water flow in dry snow. Water Resour. Res., 12, 523-527, https://doi.org/10.1029/ WR012i003p00523.

- 1991: The layered character of snow covers. Rev. Geophys., 29, 81-96, https://doi.org/10.1029/90RG02351.

Cordisco, E., C. Prigent, and F. Aires, 2006: Snow characterization at a global scale with passive microwave satellite observations. J. Geophys. Res., 111, D19102, https://doi.org/10.1029/ 2005JD006773.

Draper, D. W., D. A. Newell, F. J. Wentz, S. Krimchansky, and G. M. Skofronick-Jackson, 2015: The Global Precipitation Measurement (GPM) Microwave Imager (GMI): Instrument overview and early on-orbit performance. IEEE J. Sel. Top. Appl. Earth Obs. Remote Sens., 8, 3452-3462, https://doi.org/ 10.1109/JSTARS.2015.2403303.

Ebtehaj, A. M., and C. D. Kummerow, 2017: Microwave retrievals of terrestrial precipitation over snow-;covered surfaces: 
A lesson from the GPM satellite. Geophys. Res. Lett., 44, 6154-6162, https://doi.org/10.1002/2017GL073451.

Eriksson, P., R. Ekelund, J. Mendrok, M. Brath, O. Lemke, and S. A. Buehler, 2018: A general database of hydrometeor single scattering properties at microwave and sub-millimetre wavelengths. Earth Syst. Sci. Data, 10, 1301-1326, https://doi.org/ 10.5194/essd-10-1301-2018.

Ferraro, R. R., and Coauthors, 2005: NOAA operational hydrological products derived from the AMSU. IEEE Trans. Geosci. Remote Sens., 43, 1036-1049, https://doi.org/10.1109/ TGRS.2004.843249.

Foster, J. L., A. T. C. Chang, and D. K. Hall, 1997: Comparison of snow mass estimates from a prototype passive microwave snow algorithm, a revised algorithm and a snow depth climatology. Remote Sens. Environ., 62, 132-142, https://doi.org/ 10.1016/S0034-4257(97)00085-0.

_ , D. K. Hall, A. T. Chang, A. Rango, W. Wergin, and E. Erbe, 1999: Effects of snow crystal shape on the scattering of passive microwave radiation. IEEE Trans. Geosci. Remote Sens., 37, 1165-1168, https://doi.org/10.1109/36.752235.

Freund, Y., 2009: A more robust boosting algorithm. arXiv, 8 pp., http://arxiv.org/abs/0905.2138.

Grody, N. C., 1991: Classification of snow cover and precipitation using the Special Sensor Microwave Imager. J. Geophys. Res., 96, 7423-7435, https://doi.org/10.1029/91JD00045.

— using SSM/I measurements. IEEE Trans. Geosci. Remote Sens., 34, 237-249, https://doi.org/10.1109/36.481908.

— , and F. Weng, 2008: Microwave emission and scattering from deserts: Theory compared with satellite measurements. IEEE Trans. Geosci. Remote Sens., 46, 361-375, https://doi.org/ 10.1109/TGRS.2007.909920.

Hall, D. K., and G. A. Riggs, 2007: Accuracy assessment of the MODIS snow products. Hydrol. Processes, 21, 1534-1547, https://doi.org/10.1002/hyp.6715.

$\longrightarrow,-$, and V. V. Salomonson, 1995: Development of methods for mapping global snow cover using moderate resolution imaging spectroradiometer data. Remote Sens. Environ., 54, 127-140, https://doi.org/10.1016/0034-4257(95)00137-P.

,,,--- N. E. DiGirolamo, and K. J. Bayr, 2002: MODIS snow-cover products. Remote Sens. Environ., 83, 181-194, https://doi.org/10.1016/S0034-4257(02)00095-0.

Hallikainen, M., F. Ulaby, and M. Abdelrazik, 1986: Dielectric properties of snow in the 3 to $37 \mathrm{GHz}$ range. IEEE Trans. Antennas Propag., 34, 1329-1340, https://doi.org/10.1109/TAP.1986.1143757.

Hewison, T. J., and S. J. English, 1999: Airborne retrievals of snow and ice surface emissivity at millimeter wavelengths. IEEE Trans. Geosci. Remote Sens., 37, 1871-1879, https://doi.org/ 10.1109/36.774700.

Johnson, B. T., W. S. Olson, and G. Skofronick-Jackson, 2016: The microwave properties of simulated melting precipitation particles: Sensitivity to initial melting. Atmos. Meas. Tech., 9, 9-21, https://doi.org/10.5194/amt-9-9-2016.

Kelly, R. E., A. T. Chang, L. Tsang, and J. L. Foster, 2003: A prototype AMSR-E global snow area and snow depth algorithm. IEEE Trans. Geosci. Remote Sens., 41, 230-242, https:// doi.org/10.1109/TGRS.2003.809118.

Kim, M. J., J. A. Weinman, W. S. Olson, D. E. Chang, G. Skofronick-; Jackson, and J. R. Wang, 2008: A physical model to estimate snowfall over land using AMSU-;B observations. J. Geophys. Res., 113, D09201, https://doi.org/10.1029/2007JD008589.

Kneifel, S., U. Löhnert, A. Battaglia, S. Crewell, and D. Siebler, 2010: Snow scattering signals in ground-based passive microwave radiometer measurements. J. Geophys. Res., 115, D16214, https://doi.org/10.1029/2010JD013856.

—, J. Leinonen, J. Tyynelä, D. Ori, and A. Battaglia, 2020: Scattering of hydrometeors. Satellite Precipitation Measurement, V. Levizzani et al., Eds., Advances in Global Change Research, Vol. 67, Springer, 249-276, https://doi.org/10.1007/978-3-03024568-9_15.

Kongoli, C., and S. Helfrich, 2015: A multi-source interactive analysis approach for Northern Hemispheric snow depth estimation. 2015 IEEE Int. Geoscience and Remote Sensing Symp. (IGARSS), Milan, Italy, IEEE, 770-773, https://doi.org/ 10.1109/IGARSS.2015.7325878.

Kulie, M. S., and R. Bennartz, 2009: Utilizing spaceborne radars to retrieve dry snowfall. J. Appl. Meteor. Climatol., 48, 25642580, https://doi.org/10.1175/2009JAMC2193.1.

— — - T. J. Greenwald, Y. Chen, and F. Weng, 2010: Uncertainties in microwave properties of frozen precipitation: Implications for remote sensing and data assimilation. J. Atmos. Sci., 67, 3471-3487, https://doi.org/10.1175/2010JAS3520.1.

—, L. Milani, N. B. Wood, S. A. Tushaus, R. Bennartz, and T. S. L'Ecuyer, 2016: A shallow cumuliform snowfall census using spaceborne radar. J. Hydrometeor., 17, 1261-1279, https:// doi.org/10.1175/JHM-D-15-0123.1.

Kuo, K. S., and Coauthors, 2016: The microwave radiative properties of falling snow derived from nonspherical ice particle models. Part I: An extensive database of simulated pristine crystals and aggregate particles, and their scattering properties. J. Appl. Meteor. Climatol., 55, 691-708, https://doi.org/ 10.1175/JAMC-D-15-0130.1.

Laviola, S., J. Dong, C. Kongoli, H. Meng, R. Ferraro, and V. Levizzani, 2015: An intercomparison of two passive microwave algorithms for snowfall detection over Europe. 2015 IEEE Int. Geoscience and Remote Sensing Symp. (IGARSS), Milan, Italy, IEEE, 886-889, https://doi.org/ 10.1109/IGARSS.2015.7325907.

Levizzani, V., S. Laviola, and E. Cattani, 2011: Detection and measurement of snowfall from space. Remote Sens., 3, 145166, https://doi.org/10.3390/rs3010145.

Liu, G., 2008: Deriving snow cloud characteristics from CloudSat observations. J. Geophys. Res., 113, D00A09, https://doi.org/ 10.1029/2007JD009766.

_ 2020: Radar snowfall measurement. Satellite Precipitation Measurement, Vol. 1, V. Levizzani et al., Eds., Advances in Global Change Research, Vol. 67, Springer, 277-295, https:// doi.org/10.1007/978-3-030-24568-9_16.

_- , and E. K. Seo, 2013: Detecting snowfall over land by satellite high-;frequency microwave observations: The lack of scattering signature and a statistical approach. J. Geophys. Res. Atmos., 118, 1376-1387, https://doi.org/ 10.1002/jgrd.50172.

Markus, T., D. C. Powell, and J. R. Wang, 2006: Sensitivity of passive microwave snow depth retrievals to weather effects and snow evolution. IEEE Trans. Geosci. Remote Sens., 44, 68-77, https://doi.org/10.1109/TGRS.2005.860208.

Metsämäki, S., and Coauthors, 2015: Introduction to GlobSnow Snow Extent products with considerations for accuracy assessment. Remote Sens. Environ., 156, 96-108, https://doi.org/ 10.1016/j.rse.2014.09.018.

Milani, L., and Coauthors, 2018: CloudSat snowfall estimates over Antarctica and the Southern Ocean: An assessment of independent retrieval methodologies and multi-year snowfall analysis. Atmos. Res., 213, 121-135, https://doi.org/10.1016/ j.atmosres.2018.05.015. 
_ - V. Petkovic, and M. Orescanin, 2020: Snowfall type classification for improving passive microwave snowfall estimates. 2020 Fall Meeting, Online, Amer. Geophys. Union, Abstract A059-0012.

Munchak, S. J., S. Ringerud, L. Brucker, Y. You, I. de Gelis, and C. Prigent, 2020: An active-passive microwave land surface database from GPM. IEEE Trans. Geosci. Remote Sens., 58, 6224-6242, https://doi.org/10.1109/TGRS.2020.2975477.

Nagler, T., G. Bippus, C. Derksen, R. Fernandes, and K. Luojus, 2014: Report on 1st International Satellite Snow Products Intercomparison Workshop (ISSPI-1). ISSPI Workshop Tech. Rep., 19 pp., https://earth.esa.int/eogateway/documents/20142/ 37627/ISSPI_WORKSHOP_REPORT.pdf.

Noh, Y. J., G. Liu, A. S. Jones, and T. H. Vonder Haar, 2009: Toward snowfall retrieval over land by combining satellite and in situ measurements. J. Geophys. Res., 114, D24205, https:// doi.org/10.1029/2009JD012307.

Olson, W. S., and Coauthors, 2016: The microwave radiative properties of falling snow derived from nonspherical ice particle models. Part II: Initial testing using radar, radiometer and in situ observations. J. Appl. Meteor. Climatol., 55, 709-722, https://doi.org/10.1175/JAMC-D-15-0131.1.

Panegrossi, G., J. F. Rysman, D. Casella, A. C. Marra, P. Sanò, and M. S. Kulie, 2017: CloudSat-based assessment of GPM Microwave Imager snowfall observation capabilities. Remote Sens., 9, 1263, https://doi.org/10.3390/rs9121263.

Petty, G. W., and W. Huang, 2010: Microwave backscatter and extinction by soft ice spheres and complex snow aggregates. J. Atmos. Sci., 67, 769-787, https://doi.org/10.1175/ 2009JAS3146.1.

Pielmeier, C., and M. Schneebeli, 2003: Developments in the stratigraphy of snow. Surv. Geophys., 24, 389-416, https:// doi.org/10.1023/B:GEOP.0000006073.25155.b0.

Prigent, C., F. Aires, and W. B. Rossov, 2003: Retrieval of surface and atmospheric geophysical variables over snow-covered land from combined microwave and infrared satellite observations. J. Appl. Meteor., 42, 368-380, https://doi.org/10.1175/ 1520-0450(2003)042<0368:ROSAAG > 2.0.CO;2.

— E. Eaumouillé, F. Chevallier, and F. Aires, 2008: A parameterization of the microwave land surface emissivity between 19 and $100 \mathrm{GHz}$, anchored to satellite-derived estimates. IEEE Trans. Geosci. Remote Sens., 46, 344-352, https://doi.org/ 10.1109/TGRS.2007.908881.

Riggs, G. A., D. K. Hall, and V. V. Salomonson, 2006: MODIS snow products user guide to collection 5. NASA Tech. Doc., 80 pp., https://modis-snow-ice.gsfc.nasa.gov/uploads/ sug_c5.pdf.

Ringerud, S., C. Peters-Lidard, J. Munchak, and Y. You, 2021: Applications of dynamic land surface information for passive microwave precipitation retrieval. J. Atmos. Oceanic Technol., 38, 167-180, https://doi.org/10.1175/JTECH-D-20-0048.1.

Romanov, P., D. Tarpley, G. Gutman, and T. Carroll, 2003: Mapping and monitoring of the snow cover fraction over North America. J. Geophys. Res., 108, 8619, https://doi.org/ 10.1029/2002JD003142.

__ 2017: Global Multisensor Automated Satellite-Based Snow and Ice Mapping System (GMASI) for cryosphere monitoring. Remote Sens. Environ., 196, 42-55, https://doi.org/10.1016/ j.rse.2017.04.023.

Rott, H., and T. Nagler, 1995: Intercomparison of snow retrieval algorithms by means of spaceborne microwave radiometry. Passive Microwave Remote Sensing of Land-Atmosphere Interactions, B. J. Choudhury et al., Eds., ESA/NASA International Workshop, 227-243.
Rysman, J. F., G. Panegrossi, P. Sanò, A. C. Marra, S. Dietrich, L. Milani, and M. S. Kulie, 2018: SLALOM: An all-surface snow water path retrieval algorithm for the GPM Microwave Imager. Remote Sens., 10, 1278, https://doi.org/10.3390/ rs10081278.

— GPM Microwave Imager: A new module for the SLALOM algorithm. Geophys. Res. Lett., 46, 13 593-13 601, https:// doi.org/10.1029/2019GL084576.

Skofronick-;Jackson, G., and B. T. Johnson, 2011: Surface and atmospheric contributions to passive microwave brightness temperatures for falling snow events. J. Geophys. Res., 116, D02213, https://doi.org/10.1029/2010JD014438.

Skofronick-Jackson, G., M. J. Kim, J. A. Weinman, and D. E. Chang, 2004: A physical model to determine snowfall over land by microwave radiometry. IEEE Trans. Geosci. Remote Sens., 42, 1047-1058, https://doi.org/10.1109/TGRS.2004.825585.

—, M. Kulie, L. Milani, S. J. Munchak, N. B. Wood, and V. Levizzani, 2019: Satellite estimation of falling snow: A Global Precipitation Measurement (GPM) Core Observatory perspective. J. Appl. Meteor. Climatol., 58, 1429-1448, https:// doi.org/10.1175/JAMC-D-18-0124.1.

Stiles, W. H., and F. T. Ulaby, 1980: The active and passive microwave response to snow parameters: 1 . Wetness. J. Geophys. Res., 85, 1037-1044, https://doi.org/10.1029/JC085iC02p01037.

Takbiri, Z., A. Ebtehaj, E. Foufoula-Georgiou, P. E. Kirstetter, and F. J. Turk, 2019: A prognostic nested $K$-nearest approach for microwave precipitation phase detection over snow cover. J. Hydrometeor., 20, 251-274, https://doi.org/10.1175/JHM-D18-0021.1.

Tedesco, M., R. Reichle, A. Low, T. Markus, and J. L. Foster, 2010: Dynamic approaches for snow depth retrieval from spaceborne microwave brightness temperature. IEEE Trans. Geosci. Remote Sens., 48, 1955-1967, https://doi.org/10.1109/ TGRS.2009.2036910.

Turk, J., 2016: CloudSat-GPM coincidence dataset, version 1C. NASA Tech. Rep., 18 pp., https://pmm.nasa.gov/sites/default/ files/document_files/CSATGPM_COIN_ATBD.pdf.

Walker, A. E., and B. E. Goodison, 1993: Discrimination of a wet snow cover using passive microwave satellite data. Ann. Glaciol., 17, 307-311, https://doi.org/10.3189/S026030550001301X.

Wang, D., and Coauthors, 2017: Surface emissivity at microwaves to millimeter waves over polar regions: Parameterization and evaluation with aircraft experiments. J. Atmos. Oceanic Technol., 34, 1039-1059, https://doi.org/10.1175/JTECH-D-16-0188.1.

Wang, Y., G. Liu, E. K. Seo, and Y. Fu, 2013: Liquid water in snowing clouds: Implications for satellite remote sensing of snowfall. Atmos. Res., 131, 60-72, https://doi.org/10.1016/ j.atmosres.2012.06.008.

Weng, F., X. Zou, X. Wang, S. Yang, and M. D. Goldberg, 2012: Introduction to Suomi National Polar-;Orbiting Partnership Advanced Technology Microwave Sounder for numerical weather prediction and tropical cyclone applications. J. Geophys. Res., 117, D19112, https://doi.org/10.1029/2012JD018144.

Wood, N. B., and T. S. L'Ecuyer, 2018: Level 2C snow profile process description and interface control document, version 0 . NASA Tech. Doc., 26 pp., http://www.cloudsat.cira.colostate.edu/ sites/default/files/products/files/2C-SNOW-PROFILE_PDICD.P1_ R05.rev0_pdf.

You, Y., N. Y. Wang, R. Ferraro, and S. Rudlosky, 2017: Quantifying the snowfall detection performance of the GPM Microwave Imager channels over land. J. Hydrometeor., 18, 729-751, https://doi.org/10.1175/JHM-D-16-0190.1. 